\title{
Measuring investors' socially responsible preferences in mutual funds
}

\begin{abstract}
The aim of this study is to analyze investor behavior towards socially responsible mutual funds. The analysis is based on an experimental study where a sample of individuals takes investment decisions under different parameters of information about the investment alternatives and expected returns. In the experiment, each participant decides how to distribute an investment budget between two funds, returns on which are uncertain and change over time. Two treatments are conducted, each providing a different degree of information on the socially responsible (SR) character of one of the two investment alternatives. The results obtained suggest that although individuals' criteria for investment are essentially guided by returns and diversification, participants invest significantly more in a fund when they are explicitly informed about its SR nature. In particular, participants who declare being concerned about SR actually invest significantly more in the SR alternative. Furthermore, the level of SR faithfulness among a small group of investors is such that they invest the main share of their budget in the SR fund, even when the return differential is highly unfavorable. Providing clear information about the SR characteristics of an investment is crucial to help investors express their preferences.
\end{abstract}

Keywords: socially responsible investment, experimental method, information, investor behavior, mutual funds. JEL Classification: G23, C91, M14.

\section{INTRODUCTION}

Mutual funds make up a significant part of most developed countries' financial systems. About $45 \%$ of the households in the U.S. invest in them, according to $\mathrm{ICI}$ (2010). Investment in mutual funds is then a widespread activity which also nonspecialized subjects undertake. The growth of the mutual fund industry over recent decades highlights the ability of these funds to channel investors' money into the financial markets. As the majority of fund investors participate through employer-sponsored plans (which generally offer menus of selected funds) or through advisors, financial advice is fundamental to mutual fund investors. The significant role of mutual funds in most markets has aroused research interest, which has had considerable social and academic impact.

The growth in the mutual fund industry has also been extended to Socially Responsible Investment (SRI), an investment typology created in the USA in the beginning of the Seventies with the goal of incorporating social and environmental criteria, besides financial ones, in investment decisions. ${ }^{1} \mathrm{SRI}$ has developed into a dynamic and promising market, SRI funds being its most developed product. These funds are characterized by the development of mechanisms which inform actual and potential investors about the involvement of organizations in activities which are seen either as negative or as attractive in socially responsible terms [Michelson et al. (2004); Cullis et al. (1992)]. The practice of excluding or including companies when creating investment portfolios based on a range of social and environmental criteria is called "screening". There are two main ways of establishing whether an investment is SR. The first is to apply a negative screen, whereby certain businesses are avoided (alcohol, tobacco, gambling, etc.). The second way is to apply a positive screen to firms; in particular, those identified as engaging in SR practices are seen as more attractive investment options.

The USA is the country with the most developed SRI market. According to the USSIF (2007) report, over $10 \%$ of the capital invested by US fund managers involves SRI strategies. In Europe, SRI assets amounted to €2.7 trillion, 
representing $17 \%$ of European funds under management [European Social Investment Forum (2007)]. ${ }^{2}$ Within this context, the aim of our study is to analyze demand for mutual funds according to their social responsibility content and the information provided to investors about this feature.

Efficiency, in terms of return and risk, is a fundamental factor in choosing where to invest. However, other factors may also affect investor behavior. The interrelationship between social responsibility and investment decisions thus constitutes a promising research field. The related literature can be divided into two main groups: (a) analysis from a sociological, psychological and even philosophical perspective of investors' explanations of the position they take with regard to SRI and (b) studies of the potential opportunity costs of SRI as compared to other investments, by means of performance measures.

From the sociological perspective, many notable studies have analyzed the reasons that drive investors to choose assets according to ethical/environmental/SR criteria [Rockness and Williams (1988); MacKenzie (1998); Williams (1999); Cowton (1999)]. We find also comparative studies on the perception of what are considered to be examples of SR behavior and their use as criteria in asset selection decisions in various countries (Lewis and MacKenzie, 2000a). Studies such as Lewis and MacKenzie (2000b), which use survey methodology, have analyzed the capacity of investors to act as a pressure group to improve their position with regard to corporate social responsibility (CSR). The profile of the SR investor and how it is related to financial criteria and portfolio composition has also attracted research interest [Anand and Cowton (1993); Drexhage (1998)]. There is much debate in the literature over what defines a SR investor. Brooks (1989) defines ethical investors as those who "believe that all investments they make have an ethical dimension, that they can and should apply their ethical standards to potential investments, and that they will be more successful by applying their ethical criteria than those who do not". In the same line, research by Rosen et al. (1991) has suggested that compared to conventional investors, SR investors tend to be younger with higher levels of education, as these types of investors presumably have a greater concern for environmental issues, which is likely to be reflected in the way they select among companies and funds.

Nilsson (2009) identifies different groups of investors having different priorities with respect to return and social responsibility, thus highlighting the possibility of differentiating marketing strategies. However, he does not analyze the relevance of these different individual values on investment behavior. ${ }^{3}$ An investor opinion survey carried out by McKinsey \& Company (2002) reports that, in the Spanish market, investors would be prepared to pay an average premium of $14 \%$ for a well-governed company. However, a significant difference can appear between the willingness to pay for a SR product declared in a survey and the corresponding real buying behavior [Camacho et al. (2004)]. Hence, in the present study, actual investing behavior of subjects with different attitudes to return, risk and social responsibility is analyzed in the laboratory.

From the financial perspective, since Moskowitz (1972) there has been a long lasting debate on the relationship between social responsibility and financial performance. Even PICTET (2008) defines the over or under performance of SRI as an "eternal" question. According to Michelson et al., (2004) there are a number of reasons why SRI might do better than more standard or conventional investments. First, it is thought that higher financial returns occur because of the adoption of social screening practices. Second, SR firms can act as a positive "signal" to investors since they communicate to the market the types of factors, including their focus on sustainability and management quality, that SR firms are expected to embrace [Cullis et al. (1992)]. Gil-Bazo et al. (2010) provide evidence that investors do not pay a price, in the form of reduced performance, for investing in SRI mutual funds, finding that SRI funds outperform similar conventional funds both before and after fees. Contained within this logic is a view that SRI operates with longer time horizons than more 
conventional investment. Empirical research supports this optimism since the longer an SRI fund has been operating, the more likely it will outperform more recently established funds [Cummings (2000)].

On the contrary, some authors have pointed out that constraints to choose stocks from a narrower market universe may affect portfolio diversification and, thus, performance [Geczy et al. (2005)]. Barnett and Salomon (2006) provide an extensive review of the benefits and costs of social responsibility and their link to financial performance. More specifically, they find a non-linear relationship between social responsibility and performance of mutual funds according to screening intensity. Lee et al. (2010) also find evidence of a decrease in mutual fund performance related to screening and a curvilinear relation between screening intensity and mutual fund systematic risk.

Besides these opposite evidences, a plethora of studies reach the conclusion that SRI performance is not significantly different from other types of investments. ${ }^{4}$ Fernández and Matallín (2008) assess SR mutual funds and draw the same conclusion. Jones et al. (2008) also examine whether SRI involves a sacrifice for fund investors, finding that SRI funds underperform the market, but in economic terms, their performance is not very different from that of conventional funds. In addition, Cortez et al. (2009) find that European SR funds generally present a neutral performance in relation to both conventional and SR benchmarks.

Without the need of taking a position in this controversial debate about the relative performance of SR funds, here investing behavior is analyzed in the case when the SR fund is in an unfavorable return position with respect to its competitor. This is the case which presents higher interest, since the SR value of the investment counterbalances a return disadvantage instead of reinforcing an advantage.

The above-mentioned literature analyzes investor behavior and demand for mutual funds from an aggregate perspective. In contrast, and as a novel approach in the literature on SRI in mutual funds, this study proposes an analysis using the methodology of experimental economics, which allows to analyze actual individual level investor behavior under different conditions of the controlled variables: expected return and information provided to the investor about the SR content of the investment options faced. ${ }^{5}$ This approach is useful for evaluating the effect that the available information about the SR nature of the investment has on investor behavior and, consequently, on the demand for the funds. The empirical study was undertaken in a laboratory for experimental economics where a sample of 166 undergraduate university students made investment decisions. They faced a sequence of risk-return combinations for two funds under two different between-subjects treatments manipulating the salience of information about the SR nature of one of the funds. In contrast to what happens in surveys, these decisions had an impact on their earnings and, not less important, their decisions also determined where their individual money was actually invested.

For the specific case of mutual funds, the use of the experimental methodology is still relatively limited. ${ }^{6}$ In their study of SRI, Fernández and Merino (2005) report the abundance of surveys in the area of corporate social responsibility (CSR) and propose an experimental design from the point of view of the product/service end user. The experimental study presented hereafter focuses on individual investors in mutual funds. Murray and Vogel (1997) and Becker-Olsen et al. (2006) use a pseudo-experimental approach to evaluate stakeholder attitudes to the firm according to its CSR practices. A study closely related to ours is Webley et al. (2001) where real investors participated in a hypothetical role play facing different scenarios involving SR and non-SR funds. They could carry out their simulation with actual investors with long investment experience. However, our design improves on theirs in that the SR and non-SR investments are non hypothetical but real and have real consequences on investors' earnings. 
A fundamental issue in decision problems is the framing of the decision. There are a plethora of articles in Behavioral Finance about the framing bias: the way a problem is presented to the decision makers will affect their actions. Tversky and Kahneman (1986) already pointed out how "alternative descriptions of a decision problem often give rise to different preferences, contrary to the principle of invariance that underlies the rational theory of choice". There are studies on the effect of framing on investor behavior in stock markets [Pompian (2006)] or on the demand for mutual funds [Annaert et al. (2005); Zheng (2008); Bailey et al. (2010)]. In the context of SRI, Glac (2009) points out that the framing of the decision situation can influence the investor engagement to investing in SR assets and also the willingness to sacrifice return in exchange for social responsibility comparing with conventional investments. In her experimental survey studentparticipants are presented with a choice between a conventional asset and a SR one under three different return scenarios applying a treatment manipulation of the framing of the decision in financial, expressive or neutral terms. Our design resembles hers in that we also use two kinds of asset and we change in our treatment the framing of the decision from just providing financial data to a more informative environment about the SR character of one of the funds. However, our framing was not so expressive, as we always posed all control questions at the end of the experiment, so that the students had no clue about our interest in SRI.

The experimental results obtained here with students are consistent with Webley et al. (2001) results with professionals, especially in the loyalty of SR investors to their SRI even in adverse return situations. Also Glac (2009) results get support from our laboratory controlled experiment, particularly in that the trade-off between expected return and SRI that the participants were willing to accept was higher in the SR manipulation.

The paper is organized as follows: in the next section the theoretical framework and testable hypotheses are presented. After that, in section 3 , the design of the experiment and its implementation are outlined. The results of the experiment are then analyzed and discussed in sections 4 and 5 respectively, and finally, we acknowledge for the limitations of the study. The instructions and information leaflets used in the experiments are included in an appendix.

\section{FRAMEWORK AND HYPOTHESES}

Beal et al. (2005) propose three potential motives for SR investment: financial returns, non-wealth returns and social change. With regard to financial returns, as seen in the introduction, much of the literature finds no significant differences between SRI and non-SRI mutual fund performance. Concerning the second motive, non-wealth returns, SRI can be marketed as differentiated and attractive to a more socially responsive sector of investors despite lack of differences in return [Cowton (2004)]. The third motive, social change, drives investors who are actively socially responsible and seek out this type of investment. For the last two motives, social responsibility may be introduced as a variable in the investor's utility function within the framework of modern portfolio theory.

The foundations of portfolio theory were laid down by Markowitz (1952), and assume that investors' utility is a function of two variables: expected return and risk. Over the following decades many models were developed that incorporate other formally rational variables, especially for risk factors. However, the extensive Behavioral Finance literature focuses on how psychological variables affect investment decisions [Kahneman and Tversky (1979); Thaler (1993); Shiller (2000); Shefrin (2001); Statman (2004)]. Some of these variables may be included in the investor's utility function. In this context, Statman (1999) and Statman et al. (2008) describe a behavioral asset-pricing model that includes both utilitarian (traditional) factors and expressive or affective characteristics. 
Hence, even if, as some literature shows, financial performance and SRI might be uncorrelated, investors will increase their utility by investing in SRI. Combining this idea with the framing manipulation that we introduce experimentally in order to inform the investors about the SR nature of one of the funds leads us to Hypothesis 1 :

Hypothesis 1: Investment in the SR fund will be greater when the frame is more informative about SR.

Beal et al. (2005) point out that neutral-SR investors may be quite satisfied with small levels of SRI, regardless of the investment outcome, if they consider it for the "fun of participation" and as different from a traditional investment. In this vein, Webley et al. (2001) show that SR investors are generally committed and hold on to their SRI even if they are ethically ineffective. But even where there is a trade-off between performance and SRI, SR investors may be willing to accept a lower expected return if the investment is more socially responsible [Webley et al. (2001) and Beal et al. (2005)]. In this vein, PICTET (2008) calls for a new perspective on the stance of SRI performance, by proposing that SRI performance has two components: financial performance and extra-financial performance. The first is linked to financial variables: return and risk factors; the second is related to the social responsibility component and therefore to generating long-term positive externalities for society. Since the financial performance of SRI does not necessarily differ from that of conventional funds, overcoming this debate, it is reasonable to suggest that the total performance of SRI would be higher on aggregate.

To formalize these issues, equation [1] shows the utility function $f$ in the Markowitz (1952) classical mean-variance model. Investors maximize the utility $u$ of portfolio $p$ by increasing its expected return, $E_{p}$, and decreasing risk, $\sigma_{p}$. It is well known that, due to the trade-off between return and risk, investors will select a level of risk according to their level of risk aversion.

$$
u=f\left(E_{p}, \sigma_{p}\right)
$$

Comparing two investments with the same expected return, utility increases if risk diminishes, for instance from $\sigma_{p}>0$ to $\sigma_{p}=0$ as shown in [2]. On the other hand, comparing two investments that give the same utility in [3], it is also possible to measure the expected return or premium, $\Delta E$, that the investor requires to assume the risk.

$$
\begin{aligned}
& f\left(E_{p}, 0\right)-f\left(E_{p}, \sigma_{p}\right)=\Delta u>0 \\
& f\left(E_{p}, 0\right)=f\left(E_{p}+\Delta E, \sigma_{p}\right)
\end{aligned}
$$

Following Beal et al. (2005) and Jessen (2009), the investor's utility function can be expressed by [4], where $s_{p}$ represents the degree of $\mathrm{SR}$ of the portfolio. If $s_{p}$ is uncorrelated with return and risk, the investor will maximize overall utility by increasing SRI. This extra-financial utility depends on the investor's SR attitude. Thus, from a same value of $s_{p}$, more SR concerned investors receive a higher utility.

$$
u=f\left(E_{p}, \sigma_{p}, s_{p}\right)
$$

Analogous to the mean-variance framework, the extra-financial utility $\Delta u$ of $S R$ performance in [5] may be measured as the difference between the utility of two portfolios with the same expected return and risk, but $s_{p}>0$ and $s_{p}=0$ respectively. By comparing two investments that give the same utility in [6], it is also possible to measure the expected return or 
premium, $\Delta E$, that one investor requires from an investment in a non-SR fund. From another perspective, $\Delta E$ may be considered as the financial return an investor would be willing to sacrifice when investing in a SR investment. In this framework, the utility of $s_{p}$ and $\Delta E$ would be equivalent.

$$
\begin{aligned}
& f\left(E_{p}, \sigma_{p}, s_{p}\right)-f\left(E_{p}, \sigma_{p}, 0\right)=\Delta u>0 \\
& f\left(E_{p}, \sigma_{p}, s_{p}\right)=f\left(E_{p}+\Delta E, \sigma_{p}, 0\right)
\end{aligned}
$$

In this context, the main purpose of this paper is to analyze investors' behavior with respect to the relationship between $s_{p}$ (SR degree of the portfolio) and $\Delta E$ (SRI premium). As we already pointed out in the introduction, many studies have examined whether SRI involves a sacrifice or a premium for the investor, in the first case, whether the investor is prepared to accept a lower expected return or an increased risk for investing in SR funds. For instance, according to research by Matterson (2000), while many investors admire social responsibility and ethics, money remains their primary concern. Other research by Sparkes (1998) found that 35\% of respondents said they would invest ethically despite their returns being slightly lower than those of comparable conventional funds. Sparkes' research shows, however, that this percentage falls sharply if the return of ethical funds is significantly less than that of conventional funds. While return on investment may be less important for socially responsible investors, it clearly remains a cause for some concern. Normally, other studies usually take the form of an aggregate analysis, by comparing efficiency of SR and non-SR funds. On the contrary, in the experiment reported here we directly analyze individual investor behavior and we control for the level of SR-concern of each participant. SR concern is measured in this research according to the subjects' answers to a Likert style question in a post-experiment questionnaire. This allows us to check the following hypotheses:

Hypothesis 2: The more SR concerned investors will invest more in the SR fund than the less SR concerned when they are informed about the SR characteristics of the funds.

Investing more in the SR fund, in our design, is equivalent to investing in the less profitable alternative. As a consequence, investors who behave that way will be sacrificing return for the sake of social performance and thus their SRI premium must be greater:

Hypothesis 3: The SRI premium will be greater for SR concerned investors.

As Glac (2009) points out, the trade-off an investor is willing to accept between financial return and social performance is not independent of the level of the return involved. That is, there is an income effect: a minimum acceptable return that the investment must reach, and only as the rate of return grows will the investor be prepared to substitute more returns by SR performance. In line with this argument we propose:

Hypothesis 4: The SRI premium will grow with the level of returns of the funds.

The expected returns of the non-SR fund are always greater or equal than those of the SR fund in our experiment. However, an investment of $100 \%$ of the endowment in the expectedly most profitable fund is not highly likely, given that most people prefer to diversify their investments:

Hypothesis 5: Investment in the fund with higher expected profits is counterbalanced by the diversification effect. 
Risk aversion plays a fundamental role in financial investment decisions. In particular, Rosen et al. (1991) propose that SR investors are risk averse. In this respect, a risk aversion test was administered to the participants at the end of each session, in order to control for the effect that individuals' risk inclination has on their decisions in the experiment.

Hypothesis 6: The more risk averse investors will invest more in the SR fund than the more risk loving when they are informed about the SR characteristics of the funds.

In our experiment the SR fund always offers lower (or equal) returns than the non-SR fund. For this reason, a higher investment in the most profitable fund is expected for those participants who declared a greater concern for returns in the post-experiment questionnaire.

Hypothesis 7: The more return inclined investors will invest more in the fund with higher expected profits (non-SR fund) than the less return inclined investors.

The next section presents the methodology used to test these hypotheses. The outcome of our tests will be revealed in the section devoted to the analysis of the results.

\section{METHODOLOGY}

As mentioned above, experimental analysis methodology is used in this research. Experimental economics is an area of applied economics, since it essentially consists of performing statistical data analyses in order to test economic theories. Obligatory references for this methodology are Davis and Holt (1993), Friedman and Sunder (1994), Kagel and Roth (1995) and Bardsley et al. (2009). What differentiates this methodology from other empirical ones is that the data studied come from decisions taken by monetarily motivated participants in an environment controlled by the researcher. This control allows the researcher to design the experiment in such a way that when testing a hypothesis, it is possible to filter out the potential effect that other unwanted variables might have on the objective under study. This technique allows for observing how investor behavior changes in specific situations, and controlling the possible material and non-material incentives that might explain these decisions at any given moment. With the observations obtained, an econometric analysis is carried out to assess the significance of the results.

\subsection{Participants}

The participant-investors voluntarily enrolled in our experiments were 166 students from the Bachelor in Business Administration courses at the Universitat Jaume I in Spain. The gender proportion was quite balanced: 77 women and 89 men. Their median age was 21 years old. Even if students are not professional investors, we are interested in the valuation of the SR characteristics of a fund by the general public. Besides, various authors, such as Smith et al. (1988) and King et al. (1992), have obtained equivalent results using professionals and students by carrying out parallel experiments, and the experimental method is widely used with university students in the USA and Europe.

Money was used as a way of introducing real value to each of the decisions made, and an average of 22 euro per person was earned during the two-hour experiment (a sufficient compensation when compared with the average student wage rate). This gain can be decomposed into: i) the result of a real individual investment of $16 €$ in mutual funds, ii) the result of a lottery choice risk aversion test, and iii) a $3 €$ show-up fee. The use of money in this type of analysis is fundamental, since we want the participant-investors to take economic decisions that, like in the real world, will have consequences for 
their own financial situation, rather than declaring a hypothetical intention. The total investment in mutual funds in the real market amounted to $2,656 €(16 € \times 166$ participants).

\subsection{Experimental Design}

Two experimental between-subjects treatments were conducted. In each scenario, each investor decided how to distribute an investment of 2,656 experimental units (EU) between two mutual funds. Each 166 EU were worth 1 euro. 70 participant-investors took part in treatment 1 and 96 in treatment 2, over five experimental sessions. No participant was allowed to participate more than once. Each treatment consisted of 31 scenarios in which the participant had to divide the total investment between the two funds. ${ }^{7}$ Both funds risks were set to be the same at $2 \%$ and the funds' returns varied sequentially in each scenario (See Table 1). More precisely, scenario number 1 began with a return of $3 \%$ for both funds, with the non-SR fund return gradually increasing by $0.2 \%$ in each scenario to $5.8 \%$ in scenario 15 . At this point, in scenario 16 we equalized again the expected returns at $6 \%$, and the non-SR fund subsequently increased again its expected return by $0.2 \%$ in each scenario, up to $9 \%$ in scenario 31 . Risk remained fixed for both treatments. Our goal here was to observe any changes in the way the individual endowment was invested in one fund or the other in each scenario when the expected return varied.

In Treatment 1 (SR Evident) participants were offered a choice between two real mutual funds, a SR fund named Ethical Asset fund and a regular non SR fund, named Stable Asset fund, both with very similar commercial and financial characteristics. ${ }^{8}$ Because the Ethical Asset fund invests in firms that are considered to meet SR requirements, we henceforth refer to this fund as the SR fund, whereas the Stable Asset fund does not, and we therefore refer to it as the non-SR fund. The fact sheets given to the participants with information on the funds can be found in the Appendix. ${ }^{9}$ In particular, the SR character of the Ethical Asset fund is made explicit to the investors by the fund's name and also by adding in the SR fund's fact sheet the sentence: "As well as traditional financial criteria, the fund invests according to ethical criteria for business activity".

In Treatment 2 (SR Non-Evident) no explicit information on the SR characteristics of the SR fund was provided. A new set of participants were asked to choose between Asset $A$ and Asset $B$ funds, which were totally identical to the previous ones. That is, the two funds invested in the same firms as in the previous treatment, with Asset $B$ fund being the SR one, but no mention to SR whatsoever was made. The corresponding fact sheets can also be found in the Appendix.

(Insert Table 1)

\subsection{Procedure}

The experiments were programmed specifically in PHP and carried out in the Laboratory for Experimental Economics (LEE) at Universitat Jaume I in Castellón, Spain, a local network of 36 clients and 2 servers dedicated exclusively to economic experiments.

The participants were given a document with instructions for the experiment and the fact sheets for the mutual funds in which they could invest. The experiment was then run for each participant on an individual computer cabin visually isolated from its neighbor cabins and no communication among the participants was allowed for the duration of the experiment. A screen appeared for each scenario and the investor had to choose how to distribute the investment between the two funds, after being shown their expected return and risk values, the latter measured by standard 
deviation. As explained above, the scenarios were sequential, with a fixed risk equal between the two funds and variations in the expected returns of the funds which made the non-SR fund increasingly attractive.

Participants allocated their investment budget of 2,656 EU (16 euro) in each one of 31 scenarios. ${ }^{10}$ Once the investors had completed the sequential scenarios, they were given a test to analyze their level of risk aversion. ${ }^{11}$ Then, they completed a questionnaire to evaluate their attitude towards SRI and towards return, their knowledge of the financial markets and some control questions on the experiment. ${ }^{12}$

The investment shares on funds "Stable/A" and "Ethical/B" for each participant $i$ under each scenario $t, w_{i t A}$ and $w_{i t B}$, were recorded for both treatments "T1-Evident/T2-Non Evident". At the end of each treatment of the experiment one of the scenarios was selected as the binding one in order to make the actual investment of the participant's funds for the period of one month. We chose the scenario which resembled the most to the actual financial market situation at that moment. ${ }^{13}$ The individual shares were invested in the way each subject had chosen to invest them in the selected scenario, which was number 1 for both treatments. For operative reasons, we added up the amounts invested in each fund. After one month, given the actual returns of the two funds $r_{A}$ and $r_{B}$, the gain of each participant $i$ (in this part of the experiment) was 16 euro $\cdot\left(1+w_{i 1 A^{\bullet}} r_{A}+w_{i 1 B^{\bullet}} r_{B}\right)$. Hence the payoffs of each subject depend on her own investment decision only and on the real return of the funds.

\section{RESULTS}

\subsection{SR and non-SR investment decisions and framing effect}

Panel A of Table 2 provides an aggregate summary of the results obtained. The table shows the percentage of investment in the non-SR fund. The first column presents the average percentage for all investors and scenarios in each treatment. As expected, due to the expected return differential, on aggregate a higher percentage of the investment was made in the non-SR fund, for which the controlled expected return-risk conditions improved continuously throughout the scenarios. For example, in treatment $\mathrm{T} 1$ a $70.11 \%$ of the total budget was invested in the non-SR fund (and a corresponding $29.89 \%$ in the SR fund, which is not shown in the table). In treatment T2, in which the SR nature of one of the two funds is not explicitly declared, the average investment in the non-SR fund is higher, at $71.63 \%$. The table also shows the results for the investors whose risk-aversion test (AT) was robust. ${ }^{14}$ These investors make up by far the largest majority: $84.3 \%$ of the total of $\mathrm{T} 1$ and $73 \%$ of $\mathrm{T} 2$. As can be seen, the results are similar, except in the case of $\mathrm{T} 2$, in which the percentages of investment in the non-SR fund are higher. In the rest of the article we present only results for participants with a robust AT.

(Insert Table 2)

In Panel B of Table 2 a comparison of the percentages of investment in the non-SR fund between T1 and T2 reveals whether there are significant differences due to the information about the SR character of one of the funds provided in the fact sheets that the investor receives. The difference in the average percentage invested in the non-SR fund is negative and significant with a value of $-3.96 \%$ ( $p$-value: 0.000$)$. This indicates that, on aggregate, investors are sensitive to the information on the ethical nature of the investment since they invest significantly more in the SR fund when they are given explicit information about its ethical nature, thus confirming Hypothesis 1. 
Figure 1 and Table 2, Panel A, also show the evolution of the percentage invested in the non-SR fund over scenarios. A clear pattern emerges for the two treatments. In both period 1 and the intermediate period 16, the periods in which expected return and risk are identical for both funds, it is clearly seen how the investors split approximately $50 \%$ of their investment between the two, following a diversification-driven strategy. In scenario 1, both funds offer a $3 \%$ return and the expected return differential subsequently increases in favor of the non-SR fund, and as a result, investment in this fund also increases gradually. In scenario 16, the expected return conditions of the two funds are once again equalized, in this case with a expected return of $6 \%$. From this point on the expected return of, and therefore the investment in, the non-SR fund once again increases attaining a maximum when the expected return of the non-SR fund reaches $9 \%$ in scenario 31 . If we compute the variation between two consecutive scenarios (except between 15 and 16) the mean increase of investment in the non-SR fund is 2.16\% ( $p$-value $=0.004)$ in T1-Evident and $2.52 \%$ ( $p$-value: 0.014$)$ in T2-Non Evident. Again we observe that the information on the SR character of one of the funds has an impact in investment, lowering the rate at which investment in the non-SR fund increases with the expected return differential. We will explore the significance of this difference in the econometric analysis performed in subsection 4.3.

In both treatments, it should be noted that the average investment in the non-SR fund in scenarios 16 to 23 is lower than that for the initial scenarios 1 to 7 . For example, for treatment T2 and with robust data, there is a shift from a percentage of $71.15 \%$ in scenarios 1 to 7 , to $66.10 \%$ in scenarios 16 to 23 . Panel $C$ in Table 2 presents the differences in these percentages and its significance. This result could be due to the fact that in scenarios 16 to 23 the starting return is $6 \%$, twice that of scenarios 1 to 7 , which means that in relative terms the variation of returns has a lesser effect because the investors' satisfaction level is higher. However, if scenarios 8 to 15 are compared with 24 to 31 , the average of the latter group is similar to that of the first group or even higher, which would suggest that the effect is not linked to the fact that the return of the SR fund starts at $6 \%$ in scenario 16. What could be happening is that investor behavior in scenarios 16 to 23 may be linked to a certain compensation effect, in the sense that as the return and risk conditions become identical for the two funds, there is a certain preference to invest in the fund in which less was being invested in the previous scenarios (from 1 to 15). This effect is higher and most significant precisely in T1, where the ethical nature of the less profitable fund is made explicit. Specifically, and for the case of robust data, the average percentage of scenarios 1 to 7 in $\mathrm{T} 1$ is $68.80 \%$ and it is $59.29 \%$ for scenarios 16 to 23 , a reduction of $9.52 \%$ ( $p$-value $=0.022$ ). To a certain extent, this would imply that the investor's ethical awareness, increased thanks to the specific information provided in T1 about the SR nature of one of the funds, leads to a greater compensated inertia with a shift to higher investments in the SR fund than in the first scenarios.

It is also interesting to note that a constant $100 \%$ investment in the non-SR fund across all scenarios is hardly ever reached in either treatment: only 1 out of 129 robust participants invested always the whole endowment in the non-SR fund. While influenced by the intention to diversify, the fact that investment in the fund which is clearly superior in expected return terms hardly ever reaches $100 \%$ also reflects a certain degree of investor SR awareness. In order to observe this phenomenon much more clearly, we focus on the investor's individual behavior. For instance in T1, only 8 out of 59 robust participants (13.56\%) invested all the money in the non-SR fund in scenario 15, where the differential in return is maximum (in fact the non-SR fund is twice as profitable). In the same case, but in the T2 treatment, where the ethical nature of one of the investment alternatives was not pointed out, 18 out of the 70 robust participants $(25.71 \%)$ invested $100 \%$ in the non-SR fund in scenario 15. In fact, the number of participants investing $100 \%$ of their endowment in the non-SR fund in some scenario in the T2 treatment is higher with respect to T1 in 30 out of the 31 scenarios. Table 3 shows the percentage of investors that invest the whole endowment in the non-SR fund in some scenario. Specifically, in T2 the average percentage of investors not investing in the SR fund in some scenario is $8.8 \%$ higher than in T1, nearly double the number of subjects, this difference being statistically significant ( $p$-value: 0.000$)$. This is in line with the result 
obtained by Glac (2009) that participants in the expressive manipulation are more likely to engage in SRI than those in the financial manipulation.

(Insert Table 3)

Even more revealing is the fact that a small group of investors, with robust risk aversion test results, systematically invested more in the SR fund than in the non-SR fund, despite its poorer performance. Table 4 provides details by treatment of the percentage of highly SR faithful investors, defined as those who invested on average less than $50 \%$ of their budget in the non-SR fund; in other words, they invested on average relatively more in the SR fund despite the increasing negative differential in expected return. Overall, $4.65 \%$ of the participants behaved in this way $(6.78 \%$ in Treatment 1 versus $2.85 \%$ in Treatment 2, again double number of subjects favor the SR fund as its SR nature becomes evident).

(Insert Table 4)

\subsection{The implicit return of SRI}

In the previous section we have shown how, when SR is evident, subjects invest more in the SR fund. We now analyze investors' behavior regarding the relationship between $s_{p}$ (SR degree of the portfolio) and $\Delta E$ (SRI premium), that is, the implicit return of the SRI. To this end, expression [7] computes $E_{p t}$, the total expected return of the portfolio for the investor in each scenario $t$. For instance, in the T1 treatment:

$$
E_{p, T 1, t}=w_{N S R I, T 1, t} E_{N S R l, t}+\left(1-w_{N S R I, T 1, t}\right) E_{S R l, t}
$$

Where, $E_{N S R l, t}$ and $E_{S R I, t}$ are, respectively, the expected return for the non-SRI and SRI funds for scenario $t$ of the experiment, and $w_{N S R I, t}$ is the share of the portfolio invested in the non-SRI fund. To empirically test the framework proposed in [6] and measure $\Delta E_{t}$ corresponding to the social responsibility component of the investment, the premium for SRI is calculated comparing the total return of the portfolio in T1 (SR evident) with that in T2 (SR non-evident) in [8]. Combining [7] and [8] we get expression [9] that computes an average of this value empirically.

$$
\begin{aligned}
& \Delta E_{t}=E_{p, T 2, t}-E_{p, T 1, t} \\
& \Delta E_{t}=\left(w_{N S R I, T 2, t}-w_{N S R I, T 1, t}\right)\left(E_{N S R l, t}-E_{S R I, t}\right)
\end{aligned}
$$

The difference in the percentage of the endowment that the participants invest in the non-SR fund when they are informed about the SR nature of the alternative fund multiplied by the difference between the two funds expected returns approximates empirically the theoretical concept of the premium for SRI, or how much return are participants willing to sacrifice for every euro invested in order to make a SRI. Table 5 summarizes the results from applying [9] in each scenario, where the weights invested in the non-SR fund are the average from participants' decisions in each treatment. The values in the table are averages across scenarios. Panel A reports the results for all robust investors. The first rows show the average and the difference of the expected returns of the non-SR and SR funds, in other words, the average of $E_{N S R, t, t}$ and $E_{S R I, t .}$ The next three rows present the average percentages of investment in the non-SR fund for the two treatments, that is, the average of $w_{N S R I, T 2, t}$ and $w_{N S R I, T 1, t}$. The next row then shows the mean of the premium for SRI, $\Delta E_{t}$, over the scenarios. For all the scenarios, this premium return is $0.057 \%$, and represents $4.33 \%$ of the difference 
between the expected return of the two funds. In other words, on aggregate and on average, investors value SR at $4.33 \%$ of the gap of expected return between the non-SR and SR funds.

(Insert Table 5)

However, this evaluation may vary according investors' SR-concern. We therefore split investors' results into two groups: SR-concerned investors (59\%) are those with a score strictly higher than 3 (on a Likert-scale of 1 to 5 ) in the question related to SR attitude in the post-experiment questionnaire, and the rest (41\%), classified as non SR-concerned investors. The results are now quite interesting. Panel $B$ shows the results for SR-concerned investors and Panel C for non SRconcerned investors. SR concerned investors invest $6.71 \%$ less in the non-SR funds when SR is evident (T1 treatment); however non-SR concerned subjects invest practically the same percentage in $\mathrm{T} 1$ as in $\mathrm{T} 2$, with a difference of only $0.55 \%$. This result offers some evidence in favor of Hypothesis 2 and points in the line of Webley et al. (2001) who obtain that poor ethical fund performance does not put ethical investors off. On the other hand, it contrasts with Glac's (2009) result that CSR expectations do not alter the relationship between the framing and SRI. Indeed, her rejected hypothesis gets positive support from our data.

Besides, the SRI premium is positive and significant with a mean value of $0.11 \%$ for SR-concerned investors (Panel B), and it is not significantly different from zero for non SR-concerned investors (Panel C), which offers strong support for Hypothesis 3. In particular SR concerned investors value SRI at $7.45 \%$ of the gap between the expected return of the non-SR and the SR fund, a value which is significantly different from zero, while non SR-concerned investors do not value SRI significantly more than zero.

The above-mentioned data are values for the 31 scenarios; however is also interesting to analyze behavior across scenarios. The data show that for the later scenarios (16 to 31) SR-concerned subjects invest less in the non-SR fund than in the earlier scenarios. This may be due to the fact that in the later scenarios the SR fund yields a $6 \%$ return, in contrast to $3 \%$ in the earlier scenarios. Once SR-concerned investors attain a certain level of return, they are more sensitive and value SRI more highly, specifically $8.16 \%$ of the return differential in the last scenarios against $6.68 \%$ in the first scenarios. This evidence offers some support for Hypothesis 4 even if only for the SR-concerned investors and with a small difference. Glac (2009) gets stronger support for this hypothesis.

In short, these results obtained from testing empirically Beal et al. (2005) model are largely in line with those of Webley (2001) and Glac (2009) mainly in that SR-concerned investors find a value in SRI: SR-concerned investors are therefore willing to invest in SR even if returns are lower than in conventional funds. On the other hand, for non-SR concerned investors the SRI premium is close to zero and not significant and only the expected return is relevant.

\subsection{Econometric analysis according to investor characteristics}

In this subsection investor's behavior is analyzed using an econometric model which takes into account certain characteristics linked to their individual attitude to risk and return, and their SR-concern. These three variables (uncorrelated among them) were obtained, as we pointed out before, from the post-experiment questionnaire. Some of the results of this regression have already been outlined in the previous more descriptive and inferential analysis, but here they receive a robust and significant validation using all the data obtained from our experiment (3,979 observations). 
Panel data analysis is a useful tool for dealing with the temporal and individual dimensions of our experimental data. We report here the results of a Prais and Winsten (1954) correlated panel regression for the percentage of investment in the non-SR fund.

A Breusch and Pagan Lagrangian multiplier test for random effects allows us to reject the fixed effects model $\left(\chi^{2}=3,885\right.$ p-value: 0.000$)$. Also using a Lagrange multiplier test we reject the null of no autocorrelation $\left(\chi^{2}=674, p\right.$-value: 0.000$)$.

These problems for modeling our data in the presence of heterogeneity and autocorrelation, drive us to choose a panel corrected standard errors estimation method with a panel specific $A R(1)$ structure of the form:

$\%$ of investment in the nonSR fund ${ }_{i t}=\beta_{1} \cdot$ Return Differential ${ }_{t}+\beta_{2} \cdot$ Squared Return Differential ${ }_{t}+$ $+\beta_{3} \cdot$ Risk Inclination ${ }_{i}+\beta_{4} \cdot$ Return Inclination ${ }_{i}+\beta_{5} \cdot$ SR Concern $_{i}+\beta_{6} \cdot$ Gender $_{i}+\varepsilon_{i t}$

Where Return Differential is measured as the difference in the expected returns between the two funds, Squared Return Differential is the quadratic power of the previous variable, Risk Inclination is measured using the risk aversion test that the participants answered in the post-experiment questionnaire (values range from 1-high risk aversion to 12-high risk inclination), Return Inclination was also obtained in the post-experiment questionnaire and measures in a scale from 1 to 5 the importance that each investor assigned to return when investing, SR Concern is analogous to the previous one but we asked about the importance that the investor gave to SR characteristics of the investment, Gender takes the value 0 for male and 1 for female, and the error term follows a panel specific autoregressive structure: $\varepsilon_{i t}=\rho_{i} \cdot \varepsilon_{i t-1}$.

The regression results comparing $\mathrm{T} 1$ with $\mathrm{T} 2$ are presented in Table 6 . The basic comparison treatment chosen is $\mathrm{T} 2$, where the SR nature of one of the funds is not evident. The estimated coefficients are jointly significant: $\chi^{2}(12)=20,768$, p-value: 0.000 .

(Insert Table 6)

As shown in Table 6, for Treatment 1 (SR evident) we obtain the following estimated equation:

$\hat{\%}$ of investment in $T 1$ in the nonSR fund $_{i t}=22.16 \cdot$ Return Differential $\left.\right|_{t}-4.08 \cdot$ Squared Return Differential ${ }_{t}+$ $+1.14 \cdot$ Risk Inclination ${ }_{i}+10.25 \cdot$ Return Inclination $_{i}-2.6 \cdot$ SR Concern $_{i}+3.79 \cdot$ Gender $_{i}$

All coefficients are significant at 5\% except for gender. For Treatment 2 (SR not evident) we obtain:

$\hat{\%}$ of investment in T2 in the nonSR fund ${ }_{i t}=27.8 \cdot$ Return Differential ${ }_{t}-6.35 \cdot$ Squared Return Differential ${ }_{t}-$ $-0.89 \cdot$ Risk Inclination $+10.08 \cdot$ Return Inclination ${ }_{i}+3.31 \cdot$ SR Concern $_{i}+0.37 \cdot$ Gender $_{i}$

In the Table, besides the estimated coefficients for T2, we present the difference between each estimated coefficient for $\mathrm{T} 2$ and the corresponding coefficient for $\mathrm{T} 1$, jointly with the z-score which allows testing for the significance of this difference between both treatments. The parameter of Return Differential is significantly different only at $10 \%$, while those of Squared Return Differential, Risk Inclination and SR Concern are significantly different at 5\%. 
When SR is not evident, we observe that each $1 \%$ increase in the Return Differential between the two funds significantly raises the investment in the non-SR fund by $27 \%$. This positive impact is reduced to $22 \%$ when SR is evident, thus supporting our Hypothesis 1 that the SR nature of the investment has a genuine effect in counteracting investor preference for increased expected return (which always favors the non-SR fund in our experiment). Besides, the effect of the Return Differential is not linear, but quadratic, and it is softened as the return differential grows. This feature is captured by the negative sign of the Squared Return Differential parameter and reflects the diversification effect that prevents participants from investing their entire budget in only one fund, even at high return differentials. This observed significant effect confirms Hypothesis 5. The diversification effect is always present but it is significantly lower when the SR nature of one of the funds is evident, because the investment is already less biased towards the non-SR fund in this case.

The other parameters refer to individual characteristics of our participants. The Risk Inclination parameter estimate is negative and significant for T2, while it is positive and significant for T1. This means that when the SR nature of one of the funds is not evident, the more risk averse participants tend to invest significantly more in non-SR the fund with the higher expected returns. While in T1, where the SR nature of one fund is evident, the most risk averse participants invest significantly more in the SR fund, thus confirming Hypothesis 6. Hence the perception of which is the riskier asset is influenced by the information that the investors have about its ethical nature: SRI would be seen as less risky, maybe because it is less likely that the companies in which it invests incur in legal problems. In fact, Rosen et al. (1991) point out that SR investors are somewhat risk averse, in the sense that they are not willing to assume greater risks to obtain greater gains.

Those participants more concerned about returns invest significantly more in the non-SR fund, which always has the greater expected return, as Hypothesis 7 proposed. There are no differences in this parameter between treatments. This evidence is significant in all cases, as these individuals always invest an average of $10 \%$ more in the non-SR fund.

Gender turns out not to be relevant in our analysis, however, given that we included the results of a risk aversion test as an explanatory variable (risk inclination), the most relevant differences between the genders in fund investment decisions could have already been accounted for ${ }^{15}$.

The most interesting significant difference between the two treatments that we obtain in our experiment concerns the importance that investors give to SR. In T1, where the SR nature of one of the funds is evident, the most SR concerned investors invest significantly more in the SR fund, while in T2, where they are not informed about the SR nature of one of the funds, they end up investing relatively more in the non-SR fund. This result gives strong support for Hypothesis 2 and highlights the importance of providing investors with information about the SR characteristics of the investments at their avail so that they find it easier to express their SR preferences.

\section{DISCUSSION}

This paper analyzes individual demand for mutual funds in relation to fund's characteristics, in particular SR degree and expected return, depending on investor's individual characteristics, under differently expressive frames. An experiment was organized where participants had to decide how much of their endowment to invest into two real mutual funds. In the first treatment the SR character of one of the funds was evident in the information provided to the participants, while in the second treatment it was not. Participants in each treatment were faced with 31 sequential scenarios in which the 
expected return of the SR fund remained constant while the expected return of the non-SR fund gradually increased. In this way the SR nature of one fund had the potential to counterbalance the expected return advantage of the other.

Calculating the average for both treatments, $72.35 \%$ of the participants' endowment was invested in the non-SR fund and $27.65 \%$ in the SR fund. Only 1 out of the 129 participants invested consistently all his income in the most profitable fund, while $4.65 \%$ of the participants $(6.78 \%$ when SR was evident and $2.85 \%$ when it was not) invested on average more than $50 \%$ of their budget in the less profitable SR fund. The analysis of the results reveals that the expected return differential between the two funds is the main driving force behind investment and also diversification effects are present. In this context diversification means that, as the return differential increases across scenarios, investment in the most profitable fund increases at a decreasing rate.

Results also show how investors' decisions were guided to a certain extent by the SR character of one of the funds. There has been a long lasting debate about the existence of a trade-off between financial return and SRI. Many studies have pointed out that SRI may be attractive for investors: Sparkes (1998), Nilsson (2009), and Beal et al. (2005), even if it supposes a lower financial performance. Also using an experimental approach, Webley et al. (2001) and Glac (2009) find evidence that some investors are willing to accept a trade-off between return and SRI. As PICTET (2008) proposes, SRI will entail an extra-financial performance or premium, especially for SR concerned investors. Thus, following the model of Beal et al. (2005) and considering the work of Jessen (2009), our paper makes use of a theoretical framework that considers the SRI premium in the investor's utility function and originally proposes an empirical measurement for it.

The use of the experimental methodology provides us with an environment where individual investors' decisions are observable and individual investors' characteristics can be explored, while simultaneously the features of the available investments are controllable, allowing thus for a direct measure of the SRI premium. Moreover, in contrast with other previous works, the SR and non-SR investments are non hypothetical but real, and have real consequences for the participants. So, in our case, the experiment jumps out of the laboratory and participants know from the start that their money will be invested in real mutual funds (with different degrees of SR) in a real market. This realistic design of the decision and its consequences for the investor is a main contribution of the paper, in the sense that the decision is neither taken in an hypothetical role play [Webley et al. (2001)] nor constitutes the answer to an hypothetical questionnaire about investment attitudes towards SRI [Sparkes (1998) and McKinsey \& Company (2002)]. Also the SR characteristics of the investment are real, while in Glac (2009) the subjects know that everything is hypothetical and that their money will not be invested in the assets proposed in the study, because they are fictitious. In fact, in hypothetical contexts demand effects and socially desirable answers are much more likely to be observed [Camacho et al. (2004)].

Our results point out that on aggregate and on average, the SRI premium is $4.33 \%$ of the gap between the expected return of the non-SR and SR funds. This result confirms those of Sparkes (1998), Matterson (2000), Webley et al. (2001) and Glac (2009), who found a trade-off between financial return and SRI at the level of investors' decisions. Another contribution of the paper to this literature is to link this result to the degree of investor SR-concern. So, when investors are classified as SR-concerned or non SR-concerned (from the data of a post-experiment questionnaire), the value of the SRI premium is $7.45 \%$ for SR-concerned investors but not significantly different from zero for non SR-concerned ones. In brief, SR-concerned investors value SRI while for non SR-concerned investors financial variables are more relevant.

The paper also analyzes how the absolute level of the returns may affect the trade-off between financial return and SRI as pointed out by Sparkes (1998) and Matterson (2000) and confirming Glac's (2009) evidence on this issue. In this line, our results contribute to show how, once investors attain a certain level of return, they are more sensitive and value SRI 
more highly. According to our results, SR-concerned investors value $\mathrm{SRI}$ at $6.68 \%$ of the gap of expected return between the non-SR and SR fund for the first scenarios, where the average expected returns are $4.5 \%$ and $3 \%$ for the non-SR and SR fund respectively, but at $8.16 \%$ for the latest scenarios, where the corresponding average expected returns are $7.6 \%$ and $6 \%$.

The main results of our paper concern the effect of the frame on investors' decisions. When information on the SR degree of the funds was disclosed, overall investment on the SR fund was higher. This is in line with the result obtained by Glac (2009). However, our framing was not so expressive, as we always posed all control questions at the end of the experiment, so that the participants had no clue about our interest in SRI. Moreover, our paper contributes robust evidence to this issue from three different perspectives. First, a descriptive analysis of investors' decisions shows that on average, investment in the SR fund is about $4 \%$ higher when its SR character is evident. Second, when investors are split into SR-concerned and non SR-concerned, this percentage is $6.71 \%$ for the SR-concerned and $0.55 \%$ for the latter. Third, the econometric analysis of the investment decision based on expected return differential and investors' characteristics shows that, when the SR nature of one of the funds is evident, investors' behavior is significantly different: i) they invest relatively less in the non-SR fund for equal return differentials; and ii) the diversification effect is smaller, given that in this case investment in the non-SR fund is already smaller due to SR awareness reasons.

The paper also contributes new evidence on the SR investing behavior of subjects with different attitudes to return, risk and SR: i) Investors that are more (less) sensitive to the return variable were found to make greater (lower) investments in the fund with the higher expected returns, independently of the information provided about the SR character of the other fund. And ii) In contrast, the more (less) risk-averse investors behave differently depending on the frame. When SR is not evident, they invest significantly less (more) in the fund with the lowest expected return. On the contrary, when SR becomes evident, they invest more (less) in this fund, which is the SR fund. Thus, SRI would be seen as less risky. In fact, Rosen et al. (1991) point out that SR investors are somewhat risk averse, in the sense that they are not willing to assume greater risks to obtain greater gains. iii) Lastly, results show how more (less) SR-concerned investors invest significantly less (more) in the less profitable fund when its SR character is not evident, but when it is evident they change their behavior dramatically, investing significantly more (less) in the SR fund. This evidence provides robustness for our previous results and shows how SR-concerned investors are rational under a framework with a utility function that includes financial and SR variables. We conclude that providing clear statements in the fund information about the SR character of the investment is crucial to help investors express their SR preferences.

\section{LIMITATIONS OF THE STUDY AND FUTURE RESEARCH}

The study was undertaken with students, whose experience in investment activities is normally lower and whose valuation of SR strategies by firms could be higher than for the average citizen. However, students of business administration have some knowledge of finance and investment funds have a wide acceptance among small investors. In any case, repeating this kind of experiment with professional investors could help to measure how important the likely differences are. Also repeating the experiment in different countries could help to identify cultural differences in financial investment. Furthermore, with more experienced participants it could be highly enlightening to let them actually select the firms that would enter in their investment fund, choosing from a menu of firms pre-screened according to positive and/or negative SR criteria. 


\section{APPENDIX}

\section{Instructions}

Thank you for participating in this economic experiment on fund investment decisions. The instructions are simple and if you read them carefully you will be able to earn a considerable amount of money. You will be informed personally about your earnings and at the end of the experiment you will be paid one part in cash (for punctual attendance and lotteries) while the rest of your earnings (from the fund investment we make according to your decisions) will be paid out in a month's time, following liquidation of the investment. Your personal data will be kept completely confidential and will not be used for any purpose other than this experiment, and your name will not be linked to your decisions when the results of the experiment are published. You must not reveal your decisions to any other participant during the experimental session; any communication with other participants in the experiment will automatically lead to exclusion from the experiment, and no payment will be made to any participant who breaks this rule.

The currency used in the experiment is the experimental unit (EU), and all investments, lotteries, etc., will be expressed in terms of EU. At the end of the experiment, the EU you have obtained will be converted into euros using the following exchange rate: $166 \mathrm{EU}=1 €$. Remember, the more EU you earn, the more euros you will get.

You will make your investment decisions in various sequential scenarios. In each scenario you will have a total of 2.656 EU to invest as you choose in two different funds. Together with these instructions you have a booklet with the most relevant characteristics of each of the two funds to help you make your decision. The expected return and risk (based on the funds' past values) will also appear on your computer screen. The funds' return conditions may vary in each scenario.

Following the investment scenarios, you will be shown some lotteries; once again, you must make choices in different situations. A combination of luck and your choices will determine how much money you make in the second part of the experiment.

The experiment will end with a questionnaire in which you will be asked to give your personal details and to answer some questions related to the experiment.

At the end of this week, we will make one investment according to your investment decisions for each scenario; this investment will correspond to the scenario which best resembles to the real mutual funds we will invest in. We will invest a total of 2,656 euros, in accordance with the sum of the effective choices each one of you makes. In one month's time, we will liquidate the investment made in accordance with your decisions and you will each receive the corresponding amount due to you from the investment. Payments can be collected between 8 and 31 January from the experimenters' office.

Thank you very much for your participation 


\section{Stable Asset Fund}

\section{General Information}

Manager

Current NAV

Morgan Stanley Managemen

Fund Currency

10.86

Fund Size (Millions)

EUR

Launch date

34.34

6/4/2001

International Mixed Fixed

Income

Mixed Euros Defensive/ Euro

Morningstar Category

defensive blend

Morningstar Rating

\section{Fund objective}

The fund's investment philosophy is to maximize capital growth by optimizing the return-risk profile. This target is reached through an efficient and dynamic diversification of assets, geographical and sector distribution, etc., and by using appropriate risk controls.

\section{Return and Risk}

Information on return and volatility will be provided during the experiment

\section{Fund Composition}

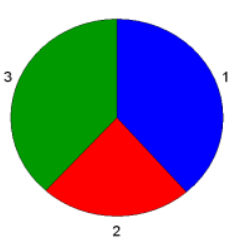

Asset Distribution

(1) Cash

(2) Equity

(3) Bonds

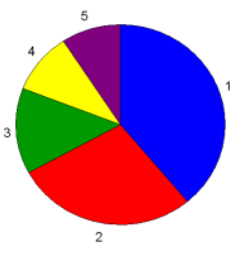

Principal Regions

(1) North America

(2) Western Europe

(3) Asia (4 Tigers)

(4) United Kingdom

(5) Japan

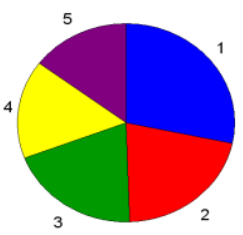

Principal Sectors

(1) Financial services

(2) Hardware

(3) Industrial goods

(4) Consumer goods

(5) Health
Total number of different equity in portfolio: 42

Total number of different Bonds in portfolio: 12

$\%$ of Assets in top 10 stocks: 35.5

\section{Manager Comment}

Long-term bond returns have fallen more than short term bond returns. This shift has been felt more sharply in Europe than in the USA. The fund also invests some of its portfolio capital in variable income securities.
Growth of

$€ 1.000$

Fondo: Morgan Stanley Fondo Activo Estable FI Acc

Categoría: Mixtos Euros Defensivos

- Indice: LB Euro-Agg. $75 \%$ / FTSE World 25\%

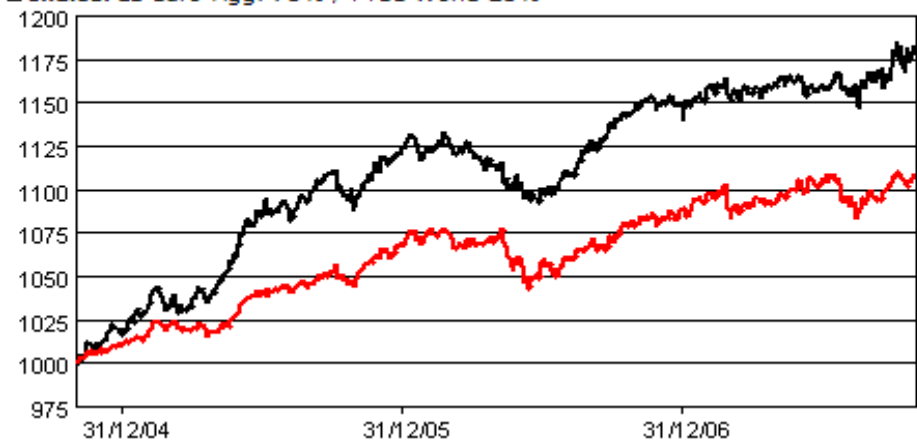

\section{Investment Style Details}

Style Box de Morningstar $(8$

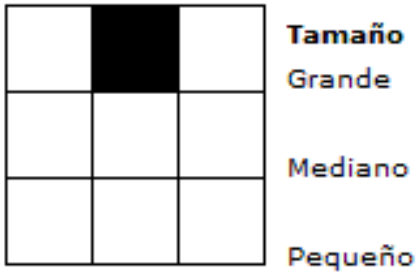

Valor Mixto Crecim

Estilo

Market Capitalization \% de RV $\begin{array}{ll}\text { Investment } \\ \text { Values }\end{array}$

Large Cap

Mid Cap

Small Cap

59.6 Price/Book Ratio

3.22

2.3 Price/Earning Ratio $\quad 15.63$

0.0 Price/Cashflow $\quad 10.07$

Size

Average market capitalization of the portfolio

\section{Top 5 Stocks}

\begin{tabular}{llr}
\hline Name & Country & \% of assets \\
\hline General Elec. Cap Corán 4.375\% 2010-01-20 & US & 6.6 \\
Bco Credito Loc 3.75\% 2011-10-20 & SV & 2.1 \\
ING (L) Renta Fd EM Debt Hd Cur P Acc & LU & 1.9 \\
INVESCO Asia Infrastructure Fund C Acc & LU & 1.5 \\
Banesto Finl 4.125\% 2009-02-12 & US & 1.5
\end{tabular}




\section{Ethical Asset Fund}

\section{General Information}

Manager

Morgan Stanley Management

Current NAV

6.81

Fund Currency

EUR

Fund Size (Millions)

15.93

Launch date

9/4/1999

INVERCO Category

Morningstar Category

International Mixed Fixed

Income

Mixed Euros Defensive

Morningstar Rating

\section{Fund objective}

The fund's investment philosophy is to maximize capital growth by optimizing the return-risk profile. This target is reached through an efficient and dynamic diversification of assets, geographical and sector distribution, etc., and by using appropriate risk controls. As well as traditional financial criteria, the fund invests according to ethical criteria for business activity.

\section{Return and Risk}

Information on return and volatility will be provided during the experiment

\section{Fund Composition}

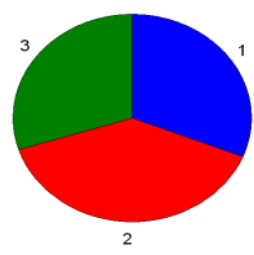

Asset Distribution

(1) Cash

(2) Equity

(3) Bonds

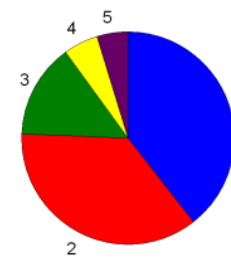

Principal Regions

(1) North America

(2) Western Europe

(3) United Kingdom

(4) South America

(5) Japan

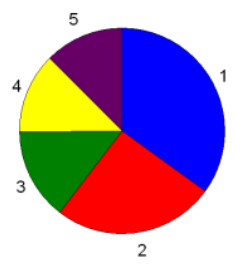

Principal Sectors

(1) Industrial goods

(2) Financial services

(3) Consumer goods

(4) Business services

(5) Hardware
Total number of different equity in portfolio: 27

Total number of different Bonds in portfolio: 9

$\%$ of Assets in top 10 stocks: 37.0

\section{Manager Comment}

Long-term bond returns have fallen more than short term bond returns. This shift has been felt more sharply in Europe than in the USA. The fund also invests some of its portfolio capital in $s$ variable income securities.

\section{Growth of $€ 1.000$}

- Fondo: Morgan Stanley Fondo Activo Etico FI Acc

Categoría: Mixtos Euros Defensivos

Indice: LB Euro-Agg. $75 \%$ / FTSE World $25 \%$

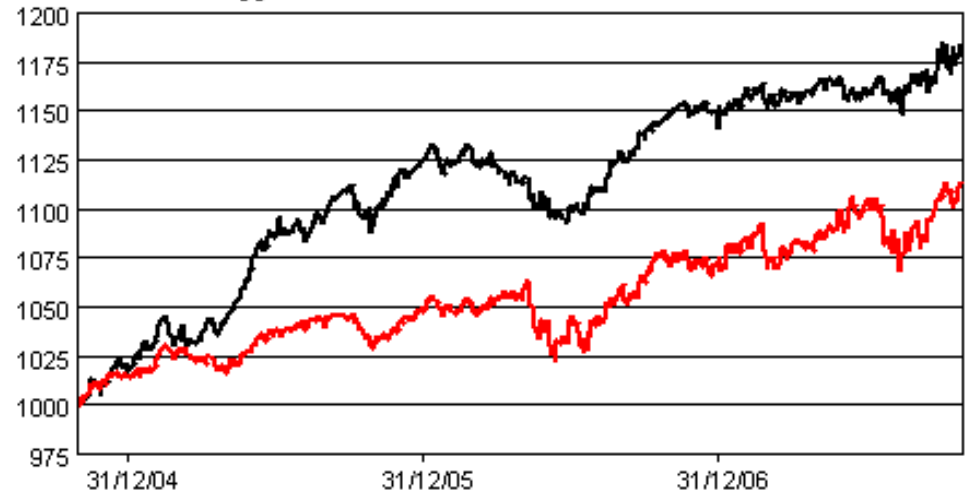

Investment Style Details

Style Box de Morningstar 8

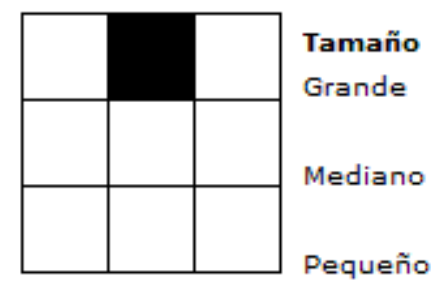

Valor Mixto Crecim

Estilo

Market Capitalization \% de RV $\begin{array}{ll}\text { Investment } \\ \text { Values }\end{array}$

Large Cap

Mid Cap

Small Cap

59.6 Price/Book Ratio

3.22

2.3 Price/Earning Ratio $\quad 15.63$

Size

0.0 Price/Cashflow

Average market capitalization of the portfolio

\section{Top 5 Stocks}

\begin{tabular}{lll}
\hline Name & Country & \% of assets \\
\hline Bayer & DE & 2.8 \\
Eli Lilly \& Company & US & 2.7 \\
Microsoft Corporation & US & 2.3 \\
Rio Tinto & GB & 2.0 \\
Xstrata & GB & 2.0
\end{tabular}




\section{Asset A Fund}

\begin{tabular}{ll} 
General Information & \\
\hline Manager & Morgan Stanley Management \\
Current NAV & 10.86 \\
Fund Currency & EUR \\
Fund Size (Millions) & 34.34 \\
Launch date & $6 / 4 / 2001$ \\
INVERCO Category & International Mixed Fixed \\
& Income \\
Morningstar Category & Mixed Euros Defensive \\
Morningstar Rating & $\star \star$ \\
\hline
\end{tabular}

\section{Fund objective}

The fund's investment philosophy is to maximize capital growth by optimizing the return-risk profile. This target is reached through an efficient and dynamic diversification of assets, geographical and sector distribution, etc., and by using appropriate risk controls.

\section{Return and Risk}

Information on return and volatility will be provided during the experiment

\section{Fund Composition}

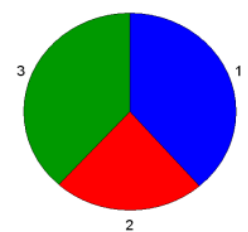

Asset Distribution

(1) Cash

(2) Equity

(3) Bonds

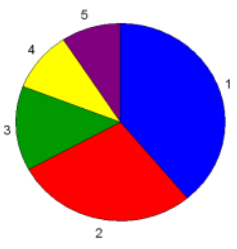

Principal Regions

(1) North America

(2) Western Europe

(3) Asia (4 Tigers)

(4) United Kingdom

(5) Japan

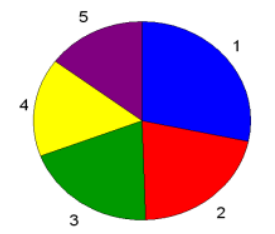

Principal Sectors

(1) Financial services

(2) Hardware

(3) Industrial goods

(4) Consumer goods

(5) Health
Total number of different equity in portfolio: 42

Total number of different Bonds in portfolio: 12

$\%$ of Assets in top 10 stocks: 35.5

\section{Manager Comment}

Long-term bond returns have fallen more than short term bond returns. This shift has been felt more sharply in Europe than in the USA. The fund also invests some of its portfolio capital in variable income securities.

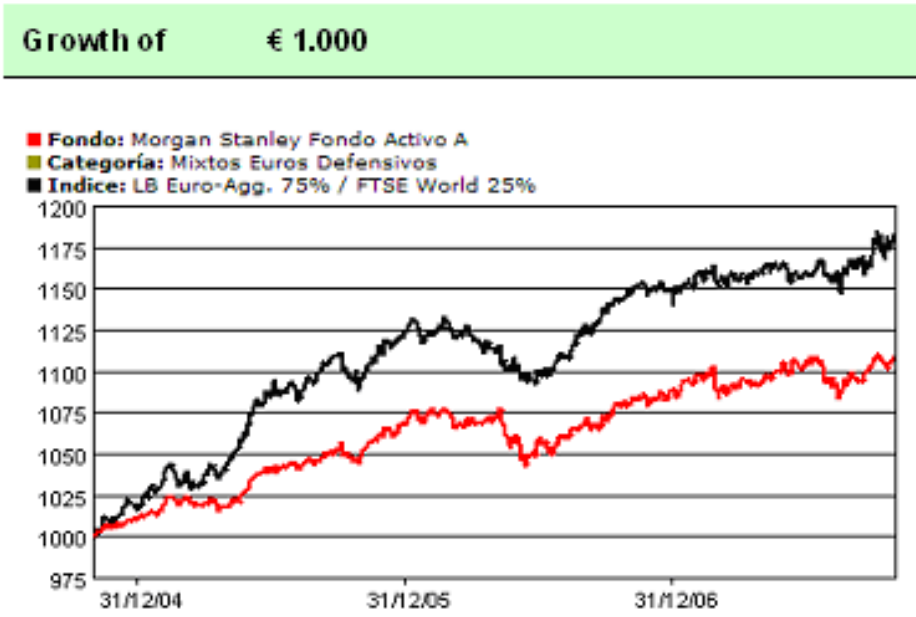

\section{Investment Style Details}

Style Box de Morningstar(8)

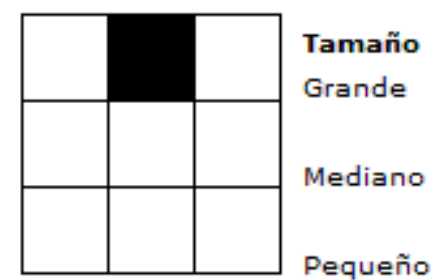

Valor Mixto Crecim

Estilo

$\begin{array}{lrlr}\text { Market Capitalization } & \text { \% de RV } & \text { Investment } & \text { Salues } \\ \text { Large Cap } & 59.6 & \text { Price/Book Ratio } & 3.22 \\ \text { Mid Cap } & 2.3 & \text { Price/Earning Ratio } & 15.63 \\ \text { Small Cap } & 0.0 & \text { Price/Cashflow } & 10.07\end{array}$

Size

Average market capitalization of the portfolio

\section{Top 5 Stocks}

\begin{tabular}{llr}
\hline Name & Country & \% of assets \\
\hline General Elec. Cap Corán 4.375\% 2010-01-20 & US & 6.6 \\
Bco Credito Loc 3.75\% 2011-10-20 & SV & 2.1 \\
ING (L) Renta Fd EM Debt Hd Cur P Acc & LU & 1.9 \\
INVESCO Asia Infrastructure Fund C Acc & LU & 1.5 \\
Banesto Finl 4.125\% 2009-02-12 & US & 1.5
\end{tabular}




\section{Asset B Fund}

\begin{tabular}{ll} 
General Information & \\
\hline Manager & Morgan Stanley Management \\
Current NAV & 6.81 \\
Fund Currency & EUR \\
Fund Size (Millions) & 15.93 \\
Launch date & $9 / 4 / 1999$ \\
INVERCO Category & International Mixed Fixed \\
Morningstar Category & Income \\
Morningstar Rating & Mixed Euros Defensive \\
\hline
\end{tabular}

\section{Fund objective}

The fund's investment philosophy is to maximize capital growth by optimizing the return-risk profile. This target is reached through an efficient and dynamic diversification of assets, geographical and sector distribution, etc., and by using appropriate risk controls.

\section{Return and Risk}

Information on return and volatility will be provided during the experiment

\section{Fund Composition}

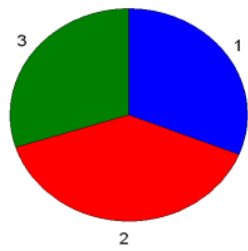

Asset Distribution

(1) Cash

(2) Equity

(3) Bonds

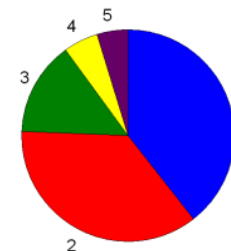

Principal Regions

(1) North America

(2) Western Europe

(3) United Kingdom

(4) South America

(5) Japan

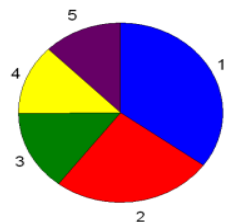

Principal Sectors

(1) Industrial goods

(2) Financial services

(3) Consumer goods

(4) Business services

(5) Hardware
Total number of different equity in portfolio: 27

Total number of different Bonds in portfolio: 9

$\%$ of Assets in top 10 stocks: 37.0

\section{Manager Comment}

Long-term bond returns have fallen more than short term bond returns. This shift has been felt more sharply in Europe than in the USA. The fund also invests some of its portfolio capital in variable income securities.

\section{Growth of $€ 1.000$}

- Fondo: Morgan Stanley Fondo Activo B

Categoría: Mixtos Euros Defensivos

Indice: LB Euro-Agg. 75\% / FTSE World 25\%

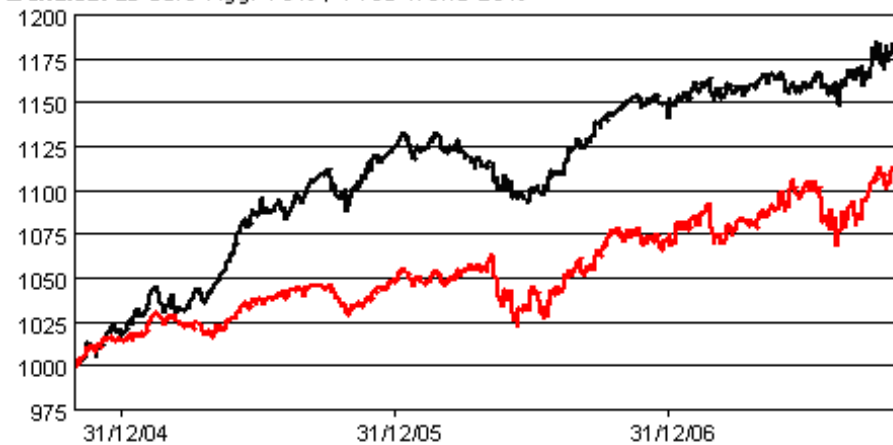

\section{Investment Style Details}

Style Box de Morningstar(8)

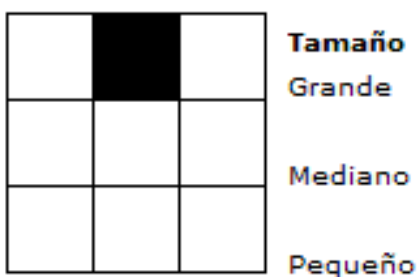

Valor Mixto Crecim

Estilo

$\begin{array}{lrlr}\text { Market Capitalization } & \text { \% de RV } & \text { Investment } & \text { Values } \\ \text { Large Cap } & 59.6 & \text { Price/Book Ratio } & 3.22 \\ \text { Mid Cap } & 2.3 & \text { Price/Earning Ratio } & 15.63 \\ \text { Small Cap } & 0.0 & \text { Price/Cashflow } & 10.07\end{array}$

Size

0.0 Price/Cashflow

Average market capitalization of the portfolio

\section{Top 5 Stocks}

\begin{tabular}{lll}
\hline Name & Country & \% of assets \\
\hline Bayer & DE & 2.8 \\
Eli Lilly \& Company & US & 2.7 \\
Microsoft Corporation & US & 2.3 \\
Rio Tinto & GB & 2.0 \\
Xstrata & GB & 2.0
\end{tabular}


${ }^{1}$ The first SR mutual fund was the Pax World Fund, which was created in 1971 in the USA to respond to investors' demand for excluding stocks from companies with an economic link to the Vietnam war.

${ }^{2}$ In Spain total investment in mutual funds amounts to 3,000 million $€$ according to the financial newspaper Expansión (12/15/2009). About one third of mutual fund investment in Spain corresponds to SRI according to Albareda and Balaguer (2006).

${ }^{3}$ In the Spanish context, one of the first studies was undertaken by Gismera and Vaquero (2000) who reported that nine out of ten Spaniards would be prepared to pay more for a product whose price included a certain amount designated to a social project, and seven out of ten would pay more for an environmentally friendly product.

${ }^{4}$ Luther et al. (1992), Mallin et al. (1995); Gregory et al. (1997), Statman (2000), Bello (2005), Kreander et al. (2005), Mill (2006), Bauer et al. (2007), and Renneboog et al. (2008).

${ }^{5}$ Experimental analysis in the area of financial economics has been extensively applied in international studies: literature reviews by Bossaerts (2001) for financial markets and by Cadsby and Maines (1998) for corporate finance provide a good overview of the wide range of use of the method in finance.

${ }^{6}$ For instance, Annaert et al.(2005) carried out an experimental study on capital guaranteed funds. Kliger et al. (2003) also opted for this approach to uncover inconsistency with the Expected Utility Theory in mutual fund investor behavior. Johnson and Tellis (2005) also study the same phenomenon experimentally, but with reference to stocks. Choi et al. (2006) design an experiment to study the role of commissions in fund investment, finding that to a large extent they are overlooked, even when they are pointed out in the information provided.

${ }^{7}$ The number of 31 scenarios was chosen as a compromise between producing high return differentials, up to $100 \%$, in small steps and obtaining a reasonable duration of the experiment for the participants: 2 hours.

${ }^{8}$ These were the actual names of the funds in the Spanish financial market.

${ }^{9}$ These fact sheets include information on the fund name, fund objective, financial indicators and portfolio composition.

${ }^{10}$ Except in the first session in which, due to technical reasons, program stopped in scenario 30.

${ }^{11}$ The risk attitude test used was the same as that used in Alfarano et al. (2006). Participants face a sequential choice between a risky and a sure option in eleven scenarios, were the risky option is kept constant and the sure option starts from a low value and sequentially increases. We record the scenario in which the sure option is chosen for the first time (the value is 12 if the subject never switches to the safe option). The latter the participant switches to the sure option, the less risk averse he is, he could even be risk-loving if he chooses to switch in scenarios greater than 8 .

${ }^{12}$ This questionnaire is available upon request from the authors.

${ }^{13}$ We were able to choose the two similar funds used in the experiment, one of them actually marketed as an ethical fund, thanks to the help of a Morgan Stanley Investment Office Director who collaborated with the study also offering advice in the selection of the investment scenario, and managing the investment and disinvestment process.

${ }^{14}$ Participants were considered robust if they did not reverse their choice once they had switched to the safe option in the risk aversion test.

${ }^{15}$ We have checked that the results of the regression do not change in any relevant way if we do not consider the variable gender. 


\section{REFERENCES}

Albareda, L. and Balaguer, M.R.: 2006, Observatorio de la Inversión Socialmente Responsable en España, ESADE.

Alfarano, S.; Barreda-Tarrazona, I. and Camacho-Cuena, E.: 2006, 'On the role of heterogeneous and Imperfect Information in a laboratory financial market', Central European Journal of Operations Research 14, 417-433.

Anand, P. and Cowton, C.: 1993, 'The ethical investor: Exploring dimensions of investment behaviour', Journal of Economic Psychology 14, 377-85.

Annaert, J.; Claes, A. and Ceuster, M.: 2005, 'Framing the individual investor: The case of capital guaranteed funds', Working Paper University of Antwerp.

Bailey, W.; Kumar, A. and Ng, D.: 2010, 'Behavioral Biases of Mutual Fund Investors', Journal of Financial Economics, forthcoming.

Bardsley, N.; Cubitt, R.; Loomes, G.; Moffatt, P.; Starmer, C. and Sugden, R.: 2009, Experimental Economics: Rethinking the Rules, Princeton University Press.

Barnett, M. and Salomon, R. : 2006, 'Beyond dichotomy: the curvilinear relationship between social responsibility and financial', Strategic Management Journal, 27, 1101-1122.

Bauer, R.; Derwall, J. and Otten, R.: 2007, 'The ethical mutual fund performance debate: New evidence from Canada', Journal of Business Ethics 70, 111-124.

Beal, D. J.; Goyen, M. and Phillips, P.: 2005, 'Why do we invest ethically?' Journal of Investing, 14 (3), 66-77.

Becker-Olsen, K.L.; Cudmore, B.A. and Hill, R.P.: 2006, 'The effect of perceived corporate social responsibility on consumer behavior', Journal of Business Research 59, 46-53.

Bello, Z.: 2005, 'Socially responsible investing and portfolio diversification', The Journal of Financial Research XXVIII, (1), $41-57$.

Bossaerts, P.: 2001, 'Experiments with financial markets: Implications for Asset Pricing Theory', The American Economist 45, 17-32.

Brooks, L.J.: 1989, 'Corporate Ethical Performance: Trends, Forecasts and Outlooks', Journal of Business Ethics, 8, 3138.

Cadsby, B.C. and Maynes, E.: 1998, 'Laboratory experiments in corporate and investment finance: a survey', Managerial and Decision Economics 19, 277-298.

Camacho-Cuena, E.; García-Gallego, A.; Georgantzís, N. and Sabater-Grande, G.: 2004, 'An experimental validation of hypothetical WTP for a recyclable product', Environmental and Resource Economics 27, 313-335.

Choi, J.; Laibson, D. and Madrian, B.: 2006, 'Why does the law of one price fail? An experiment on index mutual funds', NBER Working Papers 12261.

Cortez, M; Silva F. and Areal N.: 2009, 'The performance of European socially responsible funds', Journal of Business Research 87, 573-588.

Cowton, C.J.: 1999, 'Playing by the rules: ethical criteria at an ethical investment fund', Business Ethics: $A$ European Review 8, 60-69.

Cowton, C.J.: 2004, 'Managing financial performance at an ethical investment fund', Accounting, Auditing and Accountability Journal, 17, (2), 249-275.

Cullis, J. G.; Lewis, A. and Winnett, A.: 1992, 'Paying to be Good? U.K. Ethical Investments', Kyklos 45, (1), 3-23.

Cummings, L. A.: 2000, 'The Financial Performance of Ethical Investment Trusts: An Australian Perspective', Journal of Business Ethics 25 (1), 79-92.

Davis, D. and Holt, C.: 1993, Experimental Economics, Princeton University Press.

Drexhage, G.: 1998, 'There's money in ethics', Global Investor 109, 56.

EUSIF: 2007, Report on Socially Responsible Investing in Europe. 
Fernández, A. and Matallín J.C.: 2008, 'Performance of ethical mutual funds in Spain: sacrifice or premium', Journal of Business Ethics 81, 247-260.

Fernández-Krantz, D. and Merino-Castelló, A.: 2005, 'Is There a Willingness to pay for Corporate Social Responsibility? Consumers' Perception', Universia Business Review - Actualidad Económica, 3rd quarter, 38-53.

Friedman, D. and Sunder, S.: 1994, Experimental methods: A primer for economists, Cambridge University Press.

Geczy, C. Ch.; Stambaugh, R. F. and Levin, D.: 2005, 'Investing in Socially Responsible Mutual Funds' . Working Paper . Available at SSRN: http://ssrn.com/abstract=416380 or doi:10.2139/ssrn.416380

Gil-Bazo, J.; Ruiz-Verdú, P. and Santos, A.: 2010, 'The Performance of Socially Responsible Mutual Funds: The Role of Fees and Management Companies' Journal of Business Ethics 94, 243-263.

Gismera, L. and Vaquero, M.: 2000, 'La responsabilidad social de las empresas en España: la acción social', Papeles de Economía y Dirección 5, 1-8.

Glac, K.: 2009, 'Understanding Socially Responsible Investing: The effect of Decision Frames and Trade-off Options', Journal of Business Ethics, 87, 41-55.

Gregory, A.; Matatko, J. and Luther, R.: 1997, 'Ethical unit trust financial performance: small company effects and fund size effects', Journal of Business Finance and Accounting 24, 705-725.

Investment Company Institute: 2010, Mutual Fund Factbook, ICl.

Jessen, P.: 2009, 'Retail structured products for socially responsible investments', PRI Academic Conference Paper, Aarhus University, Denmark.

Johnson J. and Tellis, G.: 2005, 'Blowing bubbles: Heuristics and biases in the run-up of stock prices', Journal of the Academy of Marketing Science 33, 486-503.

Jones, S.; Van Der Laan, S.; Frost, G. and Loftus, J.: 2008, 'The Investment Performance of Socially Responsible Investment Funds in Australia', Journal of Business Ethics 80, 181-203.

Kagel, J. and Roth, A.: 1995, The Handbook of Experimental Economics, Princeton University Press.

Kahneman, D. and Tversky, A.: 1979, 'Prospect Theory: An Analysis of Decision under Risk', Econometrica, 47(2), 263292.

King, R.R.; Smith, V.L.; Williams, A.W. and Boening, M.V.: 1992, 'The robustness of bubbles and crashes in experimental stock market'. In Prigogine, I; Day, R. y Chen, P., eds. Nonlinear Dynamics and Evolutionary Economics. Oxford: Oxford University Press.

Kliger, D.; Levy, O. and Sonsino, D.: 2003, 'On absolute and relative performance and the demand for mutual funds experimental evidence', Journal of Economic Behavior \& Organization 52, 341-363.

Kreander, N.; Gray, R.H.; Power, D.M. and Sinclair, C.D.: 2005, 'Evaluating the performance of ethical and non-ethical funds: A matched pair analysis', Journal of Business Finance \& Accounting 32, 1465-1493.

Lee, D.; Humphrey, J.; Benson, K. and Ahn, J.: 2010, 'Socially responsible investment fund performance: the impact of screening intensity', Accounting \& Finance 50, (2), 351-370.

Lewis A. and Mackenzie C.: 2000a, 'Morals, money, ethical investing and economic psychology', Human Relations 53, 179-191.

Lewis A. and Mackenzie C.: 2000b, 'Support for investor activism among U.K. ethical investors', Journal of Business Ethics 24, 215-222.

Luther, R.G.; Matatko, J. and Corner, D.C.: 1992, 'The Investment performance of UK ethical Unit Trusts', Accounting Auditing \& Accountability Journal 5, 57-70.

Mackenzie C.: 1998, 'The choice of criteria in ethical investment', Business Ethics: A European Review 7, 81-86.

Mallin, C.A.; Saadouni, B. and Briston, R.J.: 1995, 'The financial performance of ethical investment funds', Journal of Business Finance and Accounting 22, 483-496.

Markowitz, H.: 1952, 'Portfolio Selection', Journal of Finance 7, 77-91. 
Matterson, H.: 2000, 'Ethics admirable but money comes first', The Australian, 35.

Mckinsey \& Company: 2002, Global investor opinion survey: Key Findings, www.mckinseyquaterly.com.

Michelson, G.; Wailes, N.; Van de Laan, S. and Frost, G.: 2004, 'Ethical Investment Processes and Outcomes', Journal of Business Ethics 52, 1-10.

Mill, G.A.: 2006, 'The financial Performance of a socially responsible investment over time and a possible link with social responsibility', Journal of Business Ethics 63, 131-148.

Moskowitz, M.: 1972, 'Choosing Socially Responsible Stocks', Business and Society Review, 1, $72-75$

Murray, K. and Vogel, C.: 1997, 'Using a hierarchy-of-effects approach to gauge the effectiveness of corporate social responsibility to generate goodwill toward the firm: Financial versus nonfinancial impacts', Journal of Business Research 38, 141-159.

Nilsson, J.: 2009, 'Segmenting socially responsible mutual fund investors: The influence of financial return and social responsibility', International Journal of Bank Marketing 27, 5-31

PICTET: 2008, 'The SRI performance paradox' http://www.pictet.com/en/home/about/ sustainability/sri_reports/sri_performance_paradox.print.html

Pompian M.: 2006, 'Behavioral Finance and wealth management', Wiley finance series.

Prais, S.J. and Winsten, C.B.: 1954, 'Trend estimators and serial correlation'. Cowles Commission Discussion Paper 383, Chicago.

Renneboog, L.; Horst, J.T. and Zhang, C.: 2008, 'The price of ethics and stakeholder governance of socially responsible funds', Journal of Corporate Finance 14, 302-322.

Rockness, J. and Williams, P.F.: 1988, 'A descriptive study of social responsibility mutual funds', Accounting Organizations and Society 13,397-411.

Rosen, B.N.; Sandler, DM. and Shani, D.: 1991, 'Social issues and Socially Responsible Investment Behavior: A preliminary Empirical Investigation', Journal of Consumer Affairs 25, 2, 221-234.

Shefrin, H., ed.: 2001, Behavioral Finance: A Three Volume Edited Collection. London: Edward Elgar Publishers.

Shiller, R. J.: 2000. Irrational Exuberance. Princeton, NJ Princeton University Press.

Smith, V.L.; Suchanek, G.L. and Williams, A.W.: 1988, 'Bubbles, Crashes, and Endogenous Expectations in Experimental Spot Asset Markets', Econometrica 55, 1119-1152.

Sparkes, R.: 1998, 'The Challenge of Ethical Investment: Activism, Assets and Analysis', in I. Jones and M. Pollit (eds.), The Role of Ethics in Economic Performance (Macmillan, London).

Statman, M.: 1999, 'Behavioral Finance: Past battle and future engagements', Financial Analysts Journal, November/December, 18-27.

Statman, M.: 2000, 'Socially responsible Mutual Funds', Financial Analysts Journal 56, 30-39.

Statman, M.: 2004, 'Normal Investors, Then and Now', Social Sciences Research Network (SSRN), http://papers.ssrn.com/paper.taf?abstract_id=603683.

Statman, M.; Fisher, K., and Anginer, D.: 2008, 'Affect in a behavioral asset-pricing model', Financial Analysts Journal, 64 (2), 20-29.

Thaler, R. H. (ed.): 1993, Advances in Behavioral Finance, Russel Sage Foundation.

Tversky, A. and Kahneman D.: 1986, 'Rational choice and the framing of decisions', Journal of Business 59, 251-278.

Webley, P.; Lewis, A. and Mackenzie, C.: 2001, 'Commitment among ethical investors: an experimental approach', Journal of Economic Psychology 22, 27-42.

Williams, S.: 1999, 'U.K. ethical investment: A coming of age', Journal of Investing 8, 58-75.

USSIF: 2007, Report on Socially Responsible Investing Trends in the United States.

Zheng, L.: 2008, 'The Behavior of Mutual Fund Investors', in Handbook of Financial Intermediation and Banking, ed. by A. V. Thakor, and A. W. A. Boot, pp. 259-283. Elsevier, Amsterdam. 
Table 1

Summary of the basic characteristics of the treatments carried out in the experimental analysis.

\begin{tabular}{cccccc}
\hline Treatment & $\begin{array}{c}\text { Number of } \\
\text { participants }\end{array}$ & $\begin{array}{c}\text { Number of } \\
\text { scenarios }\end{array}$ & $\begin{array}{c}\text { SR } \\
\text { evident }\end{array}$ & $\begin{array}{c}\text { SR not } \\
\text { evident }\end{array}$ & $\begin{array}{c}\text { Risk is fixed and } \\
\text { return varied for } \\
\text { non-SR fund }\end{array}$ \\
\hline 1 & 70 & 31 & $X$ & & X \\
2 & 96 & 31 & & $X$ & X \\
\hline
\end{tabular}




\section{Table 2}

Percentages of investment in the non-SR fund in the two treatments ( $T 1$ and $T 2$ ) for successive scenarios. (All observations and those showing investor robustness in the risk-aversion test (A.T.) are shown. In each scenario a choice is made between investment in the non-SR and the SR fund. Scenario number 1 begins with a return of $3 \%$ and a risk of $2 \%$ in both funds; for the non-SR fund this return gradually increases to $5.8 \%$ in scenario 15 , while the initial values remain unchanged for the SR fund. In scenario 16 both funds start with a return of $6 \%$ and a risk of $2 \%$; these values then remain constant for the SR fund, while the return on the non-SR fund rises gradually up to $9 \%$ in scenario 31 . In order to check if the differences are significant we use T-tests for two-sample means assuming unequal variances.)

Panel A

\begin{tabular}{lcrrrrr} 
& & & & & & \\
Scenarios: & Investors & 1 to 31 & 1 to 7 & 8 to 15 & 16 to 23 & 24 to 31 \\
\hline T1, SR evident & All (70) & $70.11 \%$ & $68.33 \%$ & $75.36 \%$ & $59.44 \%$ & $77.08 \%$ \\
T1, SR evident & A.T. robust (59) & $70.37 \%$ & $68.80 \%$ & $75.57 \%$ & $59.29 \%$ & $77.63 \%$ \\
T2, SR not evident & All (96) & $71.63 \%$ & $68.12 \%$ & $76.80 \%$ & $64.38 \%$ & $76.80 \%$ \\
T2, SR not evident & A.T. robust (70) & $74.33 \%$ & $71.15 \%$ & $79.83 \%$ & $66.10 \%$ & $79.83 \%$ \\
\hline
\end{tabular}

Panel B

\begin{tabular}{lccc}
\hline Scenarios: 1 to 31 & Investors & Dif. & $\begin{array}{c}\text { T test } \\
p \text {-value }\end{array}$ \\
\hline Difference $\%$ T1 - T2 & A.T. robust & $-3.96 \%$ & $(\mathbf{0 . 0 0 0})^{\star *}$ \\
\hline
\end{tabular}

Panel C

\begin{tabular}{llcl}
\hline \multicolumn{1}{c}{ Scenarios } & Investors & Dif. & \multicolumn{1}{c}{$\begin{array}{c}\text { T test } \\
\text {-value }\end{array}$} \\
\hline Difference \% T1, 1 to $7-16$ to 23 & A.T. robust & $9.52 \%$ & $(\mathbf{0 . 0 2 2})^{\star *}$ \\
Difference \% T2, 1 to $7-16$ to 23 & A.T. robust & $5.05 \%$ & $(0.185)$ \\
Difference \% T1, 8 to $15-24$ to 31 & A.T. robust & $-2.06 \%$ & $(\mathbf{0 . 0 9 5})^{*}$ \\
Difference \% T2, 8 to $15-24$ to 31 & A.T. robust & $0.00 \%$ & $(0.499)$ \\
\hline
\end{tabular}




\section{Table 3}

Percentages of participants investing their whole endowment in the non-SR fund in some scenario in T1 and T2 treatments for successive scenarios.

Panel A

\begin{tabular}{lcccccc} 
Scenarios: & Investors & 1 to 31 & 1 to 7 & 8 to 15 & 16 to 23 & 24 to 31 \\
\hline T1, SR evident & A.T. robust (59) & $10.88 \%$ & $8.72 \%$ & $12.50 \%$ & $6.14 \%$ & $15.89 \%$ \\
T2, SR not evident & A.T. robust (70) & $19.68 \%$ & $17.55 \%$ & $21.25 \%$ & $15.18 \%$ & $24.46 \%$ \\
\hline
\end{tabular}

Panel B

\begin{tabular}{lccc} 
Scenarios: 1 to 31 & Investors & Dif. & $\begin{array}{c}\text { T test } \\
p \text {-value }\end{array}$ \\
\hline Difference $\%$ T1 $1-$ T2 & A.T. robust & $-8.80 \%$ & $(\mathbf{0 . 0 0 0})^{\star *}$ \\
\hline
\end{tabular}

Table 4

Number of highly SR faithful investors, defined as those who invested on average less than $50 \%$ of their money in the non-SR fund.

\begin{tabular}{lccc}
\hline & $\begin{array}{c}\text { \# SR faithful } \\
\text { investors }\end{array}$ & $\begin{array}{c}\text { Total AT } \\
\text { robust }\end{array}$ & $\%$ \\
\hline T1, SR evident & 4 & 59 & $6.78 \%$ \\
T2, SR not evident & 2 & 70 & $2.85 \%$ \\
\hline T1,T2 & 6 & 129 & $4.65 \%$ \\
\hline
\end{tabular}


Table 5

The table compares the results from T1 (SR evident) and T2 (SR non-evident). All the data are averages of the values in the corresponding scenarios. The weights are also the average for the corresponding investors and scenarios. The table shows the mean of the SRI premium estimated using expression [9] and the mean of the premium over the difference between the expected return of the non-SR fund and the SR fund in each scenario. Panel A shows the results for all robust investors. Below, these investors are split into Panel B (C) according to their attitude towards SRI. Those participants scoring four or five out of five in the Likert-scale question about their attitude to SRI are considered SR concerned. The p-values correspond to the t-test against a mean of zero.

Panel A (All A.T. robust investors)

\begin{tabular}{|c|c|c|c|c|}
\hline & & $\begin{array}{c}\text { Scenarios } \\
1-31\end{array}$ & $\begin{array}{c}\text { Scenarios } \\
1-15\end{array}$ & $\begin{array}{c}\text { Scenarios } \\
16-31\end{array}$ \\
\hline$E_{N S R I}($ Expected return non-SRI $)$ & & $6.00 \%$ & $4.50 \%$ & $7.60 \%$ \\
\hline$E_{S R I}($ Expected return SRI) & & $4.55 \%$ & $3.00 \%$ & $6.00 \%$ \\
\hline Difference (a) & & $1.45 \%$ & $1.50 \%$ & $1.60 \%$ \\
\hline$w_{N S R l, T 2}($ SR not evident) & & $74.33 \%$ & $77.74 \%$ & $74.86 \%$ \\
\hline$W_{N S R I, T 1}$ (SR evident) & & $70.37 \%$ & $73.66 \%$ & $70.31 \%$ \\
\hline Difference & & $3.96 \%$ & $4.09 \%$ & $4.56 \%$ \\
\hline SRI Premium & $p$-value & $\begin{array}{c}0.057 \% \\
(\mathbf{0 . 0 0 0})^{\star *}\end{array}$ & $\begin{array}{c}0.061 \% \\
(\mathbf{0 . 0 0 0})^{\star *}\end{array}$ & $\begin{array}{c}0.053 \% \\
(0.000)^{* *}\end{array}$ \\
\hline SRI Premium / (a) & $p$-value & $\begin{array}{c}4.33 \% \\
(0.000)^{\star \star}\end{array}$ & $\begin{array}{c}4.09 \% \\
(0.000)^{\star \star}\end{array}$ & $\begin{array}{c}4.56 \% \\
(0.000)^{\star \star}\end{array}$ \\
\hline
\end{tabular}

Panel B (SR concerned investors)

\begin{tabular}{|c|c|c|c|c|}
\hline & & $\begin{array}{c}\text { Scenarios } \\
1-31\end{array}$ & $\begin{array}{c}\text { Scenarios } \\
1-15\end{array}$ & $\begin{array}{c}\text { Scenarios } \\
16-31\end{array}$ \\
\hline$w_{N S R I, T 2}$ (SR not evident) & & $75.12 \%$ & $78.374 \%$ & $76.266 \%$ \\
\hline$w_{N S R I, T 1}($ SR evident) & & $68.40 \%$ & $71.695 \%$ & $68.102 \%$ \\
\hline Difference & & $6.71 \%$ & $6.68 \%$ & $8.16 \%$ \\
\hline SRI Premium & $p$-value & $\begin{array}{c}0.112 \% \\
(0.000)^{\star *}\end{array}$ & $\begin{array}{c}0.095 \% \\
(\mathbf{0 . 0 0 0})^{\star \star}\end{array}$ & $\begin{array}{c}0.127 \% \\
(0.000)^{\star *}\end{array}$ \\
\hline SRI Premium / (a) & $p$-value & $\begin{array}{c}7.447 \% \\
(\mathbf{0 . 0 0 0})^{\star *}\end{array}$ & $\begin{array}{c}6.679 \% \\
(0.000)^{\star *}\end{array}$ & $\begin{array}{c}8.164 \% \\
(0.000)^{\star *}\end{array}$ \\
\hline
\end{tabular}

Panel C (not SR concerned investors)

\begin{tabular}{|c|c|c|c|c|}
\hline & & $\begin{array}{c}\text { Scenarios } \\
1-31\end{array}$ & $\begin{array}{c}\text { Scenarios } \\
1-15 \\
\end{array}$ & $\begin{array}{c}\text { Scenarios } \\
16-31\end{array}$ \\
\hline$w_{N S R I, T 2}$ (SR not evident) & & $73.60 \%$ & $77.149 \%$ & $73.578 \%$ \\
\hline$W_{N S R I, T 1}($ SR evident) & & $73.05 \%$ & $76.324 \%$ & $73.302 \%$ \\
\hline Difference & & $0.55 \%$ & $0.83 \%$ & $0.28 \%$ \\
\hline SRI Premium & $p$-value & $\begin{array}{c}-0.009 \% \\
(0.560)\end{array}$ & $\begin{array}{l}0.019 \% \\
(0.235)\end{array}$ & $\begin{array}{c}-0.035 \% \\
(0.171)\end{array}$ \\
\hline SRI Premium / (a) & $p$-value & $\begin{array}{l}0.541 \% \\
(0.410) \\
\end{array}$ & $\begin{array}{l}0.825 \% \\
(0.418)\end{array}$ & $\begin{array}{c}0.276 \% \\
(0.843) \\
\end{array}$ \\
\hline
\end{tabular}




\section{Table 6}

The Table shows the estimation of the econometric model for the percentage of investment in the non-SR fund presented in Equation 10, considering both T1 (SR Evident) and T2 treatments (SR not evident), according to temporal and individual variables, for investors with robust responses to the risk-aversion test. We present here the estimated coefficients for $\mathrm{T} 2$ and the differences with respect to them for the coefficients of T1. Prais-Winsten regression, correlated panels corrected standard errors (PCSEs) for Percentage of Investment in the non-SR fund. Number of obs. = 3,979; Number of groups $=129 ; 59$ robust participants in $\mathrm{T} 1$ and 70 robust participants in T2; Panels: independent (unbalanced); Obs. per group: $\min =30 ;$ avg. $=30.84 ;$ max. $=31$; Autocorrelation: panel-specific $\operatorname{AR}(1)$; Estimated covariances $=1 ;$ Estimated autocorrelations $=129 ;$ Estimated coefficients $=12 ; R^{2}=0.83 ;$ Wald $\chi^{2}(12)=20,768 ;$ Prob $>\chi^{2}=0.000 ; \rho_{i}=0.094,1,0.771,0.638,0.727, \ldots, 0.066$.

\begin{tabular}{|c|c|c|c|c|c|}
\hline Variable & Coefficient & $\begin{array}{c}\text { Estimated } \\
\text { Value }\end{array}$ & $\begin{array}{c}\text { Standard } \\
\text { Error }\end{array}$ & Z-statistic & $p$-value \\
\hline \multirow[t]{2}{*}{ Return differential } & $\beta_{1, \text { T2 }}$ & 27.81 & 2.18 & 12.76 & $(0.000)^{\star *}$ \\
\hline & $\beta_{1, T 1}-\beta_{1, T 2}$ & -5.64 & 3.16 & -1.79 & $(0.074)^{*}$ \\
\hline \multirow[t]{2}{*}{ Squared return diff. } & $\beta_{2, \text { T2 }}$ & -6.36 & 0.75 & -8.52 & $(0.000)^{\star *}$ \\
\hline & $\beta_{2, T 1}-\beta_{2, \text { T2 }}$ & 2.27 & 1.07 & 2.12 & $(0.034)^{\star *}$ \\
\hline \multirow[t]{2}{*}{ Risk inclination } & $\beta_{3, T 2}$ & -0.89 & 0.37 & -2.39 & $(0.017)^{\star *}$ \\
\hline & $\beta_{3, T 1}-\beta_{3, T 2}$ & 2.04 & 0.59 & 3.45 & $(0.001)^{\star *}$ \\
\hline \multirow[t]{2}{*}{ Return inclination } & $\beta_{4, T 2}$ & 10.08 & 0.71 & 14.27 & $(0.000)^{\star \star}$ \\
\hline & $\beta_{4, T 1}-\beta_{4, T 2}$ & 0.18 & 1.10 & 0.16 & $(0.874)$ \\
\hline \multirow[t]{2}{*}{ SR concern } & $\beta_{5, T 2}$ & 3.31 & 0.68 & 4.89 & $(0.000)^{\star \star}$ \\
\hline & $\beta_{5, T 1}-\beta_{5, T 2}$ & -5.91 & 1.16 & -5.09 & $(0.000)^{\star \star}$ \\
\hline \multirow[t]{2}{*}{ Gender } & $\beta_{6, T 2}$ & 0.37 & 1.42 & 0.26 & $(0.796)$ \\
\hline & $\beta_{6, T 1}-\beta_{6, \text { T2 }}$ & 3.43 & 2.16 & 1.59 & $(0.112)$ \\
\hline
\end{tabular}


Figure 1

Percentages of investment in the non-SR fund for each treatment (T1 / SR Evident and T2 / SR Not Evident). Scenario number 1 begins with a return of $3 \%$ and risk of $2 \%$ in both funds; in the non-SR fund this return gradually increases to $5.8 \%$ in scenario 15 , while the initial values remain unchanged for the ethical fund. In scenario 16 both start with a return of $6 \%$ and risk of $2 \%$; these values then remain constant for the SR fund, while the return on the non-SR fund rises up to $9 \%$ in scenario 31 .

$\%$ investment in the non-SR fund

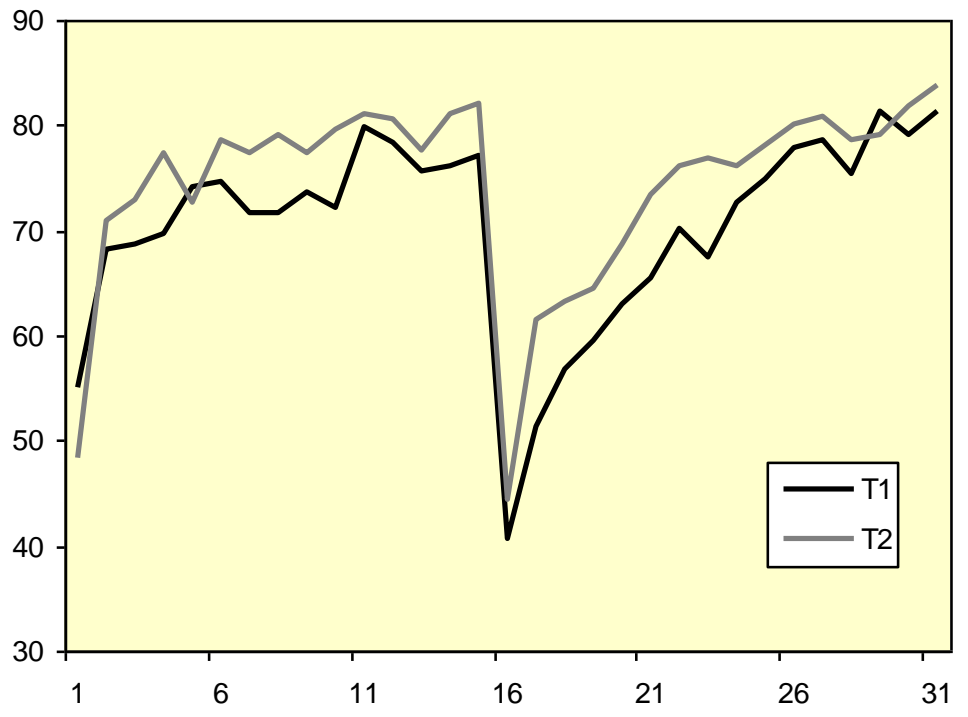

Scenarios 